\author{
Technical Paper
}

\title{
Key geomechanical properties of the historically liquefiable TP-Lisbon sand is
}

\author{
Fausto Molina-Gómez*, António Viana da Fonseca \\ CONSTRUCT-GEO, Faculdade de Engenharia da Universidade do Porto (FEUP), Portugal
}

Received 4 August 2020; received in revised form 18 March 2021; accepted 25 March 2021

Available online 28 April 2021

\begin{abstract}
The intrinsic properties of sands have a strong influence on the behaviour of these soils. Therefore, particle shape and granular packing can provide relevant insights into the mechanical properties of granular geomaterials. This study presents the characterisation of the key mechanical geomechanical properties controlling the behaviour of an alluvial fine sand, which composes the liquefiable layer of the geological profile at 'Praça do Comercio' square, located in the downtown of Lisbon (Portugal). For this purpose, a comprehensive experimental plan was conducted in the laboratory using accurate testing procedures. The experimental plan addressed: $(i)$ the evaluation of the particle shape from a large number of particles using a computational geometry algorithm and statistical procedures; (ii) the estimation of the minimum and maximum void ratio through two standard methods; (iii) the assessment of the stress-strain behaviour by triaxial tests using lubricated end platens and an embedded connection piston, and void ratio measurements using end-of-test soil freezing; and (iv) the stress-dependency assessment of seismic wave velocities using bender elements. Results are interpreted within the critical state soil mechanics framework, highlighting the effects of the particle shape and granular package on the behaviour of this natural sand. In addition, critical state and small-strain parameters are compared and thoroughly discussed against selected data of other sands. Results provide experimental evidence about the influence of the particle shape and granular packing on the key geomechanical properties of TP-Lisbon sand.

(c) 2021 Production and hosting by Elsevier B.V. on behalf of The Japanese Geotechnical Society. This is an open access article under the CC BYNC-ND license (http://creativecommons.org/licenses/by-nc-nd/4.0/).
\end{abstract}

Keywords: Sands; Laboratory tests; Shear strength; Critical state soil mechanics; Particle-scale behaviour

\section{Introduction}

Critical state soil mechanics (CSSM) is an effective and useful conceptual framework for modelling soil behaviour. A soil reaches the critical state when it 'continues to deform at constant stress and constant volume' (Roscoe et al., 1958), converging to a unique critical state locus (CSL). Hence, the critical state of soils can be represented in the three-dimensional invariant space of shear-confinement-

Peer review under responsibility of The Japanese Geotechnical Society.

* Corresponding author at: Faculdade de Engenharia da Universidade do Porto, Rua Dr. Roberto Frias, s/n 4200-465, Porto, Portugal.

E-mail address: fausto@fe.up.pt (F. Molina-Gómez). volume state, $e: p^{\prime}: q$. This space conducts to two projections in two-dimensional projections, which depends on the mean effective stress $\left(p^{\prime}\right)$, the shear or deviatoric stress $(q)$ and the void ratio of the soil $(e)$. The projection of CSL in the $p^{\prime}: q$ stress invariant space corresponds to a straight line, which is related with critical state angle $\left(\phi_{c s}\right)$, and defines the ultimate strength parameter $M$; while the projection of this CSL in the $e: \log p^{\prime}$ invariant space leads also to a straight line defined by its slope $\lambda$ and the intercept $\Gamma$. Nevertheless, $\Gamma$ can be selected for specific reference values of $p^{\prime}$ (Torres-Cruz \& Santamarina, 2020), usually $1 \mathrm{kPa}$ but sometimes 10 or $100 \mathrm{kPa}$.

Overall, the position of the CSL in granular soils is independent of initial soil fabric (Been, et al., 1991; Carrera 


\section{List of notation}

$A \quad$ area of the particle

$A_{p} \quad$ projected area of the particle

$C$ parameter of normalised small-strain shear modulus

Cc compression index

$\mathrm{Ce}$ expansion index

$\mathrm{Ci} \quad$ circularity of particles

$\mathrm{Cr}$ recompression index

$\mathrm{Cu}$ coefficient of uniformity

$C x \quad$ convexity of particles

$C z \quad$ coefficient of curvature

$D \quad$ soil density

$D_{50} \quad$ mean diameter

$\mathrm{Dr} \quad$ relative density

$d \quad$ dilation rate

$d_{m} \quad$ maximum dilation rate

$e \quad$ void ratio

$e_{0} \quad$ initial void ratio

$e_{c s} \quad$ void ratio at critical state

$e_{\max }$ maximum void ratio

$e_{\text {min }} \quad$ minimum void ratio

Gs specific gravity of solid particles

$L_{t t} \quad$ tip-to-tip distance between bender elements

$M \quad$ slope of critical state locus in $p^{\prime}: q$ space

$N \quad$ volumetric coupling parameter

$N c \quad$ number of particle corners

$n \quad$ Exponent of normalised small-strain shear modulus

$p^{\prime} \quad$ mean effective stress $p_{0}^{\prime} \quad$ mean effective stress after consolidation

$p_{c s}^{\prime} \quad$ mean effective stress at critical state

$P_{p} \quad$ projected perimeter of the particle

$q \quad$ deviatoric stress

$q_{c s} \quad$ deviatoric stress at critical state

$R \quad$ roundness

$S \quad$ sphericity

$t_{t} \quad$ travel time of wave propagation

$V s \quad$ shear wave velocity

Vp compression wave velocity

$\alpha \quad$ shear wave velocity factor at $1 \mathrm{kPa}$

$\beta \quad$ stress-dependency exponent of wave velocities

$\Delta u \quad$ pore-pressure change

$\Gamma \quad$ intercept of critical state in $e: \log p^{\prime}$ space

$\varepsilon_{a} \quad$ axial strain

$\varepsilon_{v} \quad$ volumetric strain

$\varepsilon_{s} \quad$ deviatoric strain

$\eta \quad$ stress ratio

$\eta_{\max } \quad$ peak stress ratio

$\theta \quad$ compression wave velocity factor at $1 \mathrm{kPa}$

$\lambda \quad$ slope of critical state in $e: \log p^{\prime}$ space

$v \quad$ Poisson ratio

$\rho \quad$ regularity

$\sigma_{\mathrm{v}}^{\prime} \quad$ vertical effective stress

$\phi_{c s} \quad$ angle of friction in the critical state

$\chi \quad$ dilatancy rate scaling parameter

$\psi \quad$ state parameter

$\psi_{\mathrm{d}} \quad$ state parameter at $d_{m}$ et al., 2011; Ishihara, 1993; Li et al., 2018; Papadimitriou et al., 2005; Shipton \& Coop, 2012). However, the CSL and geomechanical behaviour of sands depend on some intrinsic properties, which are represented by the particle dimension, particle shape and the granular packing. In this sense, nowadays, there is an interest to correlate the geomechanical properties of granular soils with their morphological properties to obtain relevant insights, which aid in understanding the behaviour of these materials.

Cho et al. (2006), Yang \& Luo (2015), Altuhafi et al. (2016), Sarkar et al. (2019) and Lashkari et al. (2020) proposed correlations between critical state parameters with the particle shape of sands. The main findings of these studies were similar -particle shape can significantly alter the critical state parameters of granular soils- although included the measurement of morphological properties by different methods (e.g. visual approach and advanced imaging analysis). The effects of particle shape on critical state parameters were recently validated by numerical simulations comprising discrete element methods, DEM, (e.g. Jiang et al., 2018; Nguyen et al., 2020). Consequently, the morphological properties provide micromechanical approximations toward explaining complex phenomena of granular materials interpreted by the CSSM framework, such as soil liquefaction (Wei \& Yang, 2014; Yang \& Wei, 2012) and dilatancy (Winter et al., 2017; Xiao et al., 2019).

On the other hand, particle shape has a strong influence on the packing of granular materials (Cubrinovski \& Ishihara, 2002; Santamarina \& Cho, 2004; Sarkar et al., 2020); for example, non-spherical and uniform-sized sands tend to have larger values of $e_{\max }$ and $e_{\min }$ than rounded, spherical, and well-graded sands (Zheng \& Hryciw, 2016; Zheng et al., 2017). Granular packing, represented by the extreme void ratios in sandy soils, captures the underlying role on the volumetric compression potential and allows identifying the potential position of CSL (Torres-Cruz \& Santamarina, 2020). Moreover, it is well-known that the granular packing together with the particle shape has a strong influence on the stress-dependency of small-strain stiffness of sands because of the contact-type and arrangement of soil particles (Altuhafi et al., 2016; Cho et al., 2006; Liu \& Yang, 2018). Therefore, there is an interest on the part of geotechnical research in assessing the influence of the morphology of soil particles on the geomechanical properties of granular soils. 
This paper presents the results of a comprehensive experimental study aimed at assessing the mechanical behaviour of the fine sand composing the liquefiable layer at the 'Praça do Comércio' site (Lisbon), which is locally denominated as Terreiro do Paço since this site was the King's palace courtyard before 1755 . Terreiro do Paço sand (hereafter referred as TP-Lisbon sand) is a historically liquefiable soil that has experienced liquefaction during the 1755 earthquake (Couto et al., 2020; Jorge \& Vieira, 1997). Such a seismic event is a well-known major earthquake ( $M=8.5$ ) occurred in the Portuguese onshore mainland, which induced the collapse of several buildings in Lisbon, emphasising the King's palace. Index properties and mechanical parameters of TP-Lisbon sand have been interpreted from laboratory tests on remoulded specimens. The main features of the behaviour of this relevant Portuguese soil are described and discussed, drawing together the results of testing within the CSSM framework. This research provides a detailed geotechnical database that add new experimental evidence about the mechanical behaviour of sandy soils, highlighting the effects of the particle shape and granular packing on the critical state and stressdependency of small-strain stiffness for TP-Lisbon sand.

\section{Materials and experimentation}

\subsection{Soil description}

TP-Lisbon sand is an alluvial soil from the Tagus River, which was sedimented in the historical centre of Lisbon during the late Quaternary. This soil is resting over glacial Miocene deposits of stiff clays (Miranda et al., 2020). Shallow layers are composed by fine clean sands and sandy silts with intercalations of plastic soils (Couto et al., 2020). The presence of such intercalations seems to indicate that the valley was infilled in a heterogeneous process, corresponding to tidal variations in the Tagus River. These layers of sandy soils (including TP-Lisbon sand) are bellow Praça do Comércio, which is one of the most historically relevant sites in Portugal and one of the loveliest squares in Europe. Fig. 1 schematises the lithological profile of the Praça do Comércio site.

Praça do Comércio site is located in the mainland region with probably the greater seismic risk of Portugal. Such a seismic risk is attributed to the proximity of the Lisbon area to the boundary of African and Eurasian plates. There is historical evidence about the occurrence of medium to large magnitude seismic events $(M>6)$ that have induced soil liquefaction in this region (Ferreira et al., 2020). An example of earthquake-induced liquefaction is the 1755 earthquake $(M=8.5)$, which almost destroyed the centre of Lisbon (Couto et al., 2020). Table 1 summarises the parameters to compute the peak ground acceleration $\left(a_{\max }\right)$ of the Lisbon area according to EC8-NA (CEN, 2010) for a return period of 475 years.

As referred before, TP-Lisbon sand is a historically liquefiable soil, which has been recently the spotlight of very

Table 1

Calculation of $\mathrm{a}_{\max }$ for Lisbon area, according to EC8-NA (CEN, 2010).

\begin{tabular}{lll}
\hline & Seismic action Type 1 & Seismic action Type 2 \\
\hline Seismic zone & 1.3 & 2.3 \\
$M_{w}$ & 7.5 & 5.2 \\
$a_{g} R\left(\mathrm{~m} / \mathrm{s}^{2}\right)$ & 1.5 & 1.7 \\
$\gamma I$ & 1 & 1 \\
$a_{g}$ & 1.0 & 1.7 \\
Ground type & $\mathrm{D}$ & $\mathrm{D}$ \\
$S_{\max }$ & 2 & 2 \\
$S_{f}$ & 1.83 & 1.77 \\
$a_{\max }\left(\mathrm{m} / \mathrm{s}^{2}\right)$ & 2.75 & 3.00 \\
$a_{\max }(\mathrm{g})$ & 0.28 & 0.31 \\
\hline
\end{tabular}

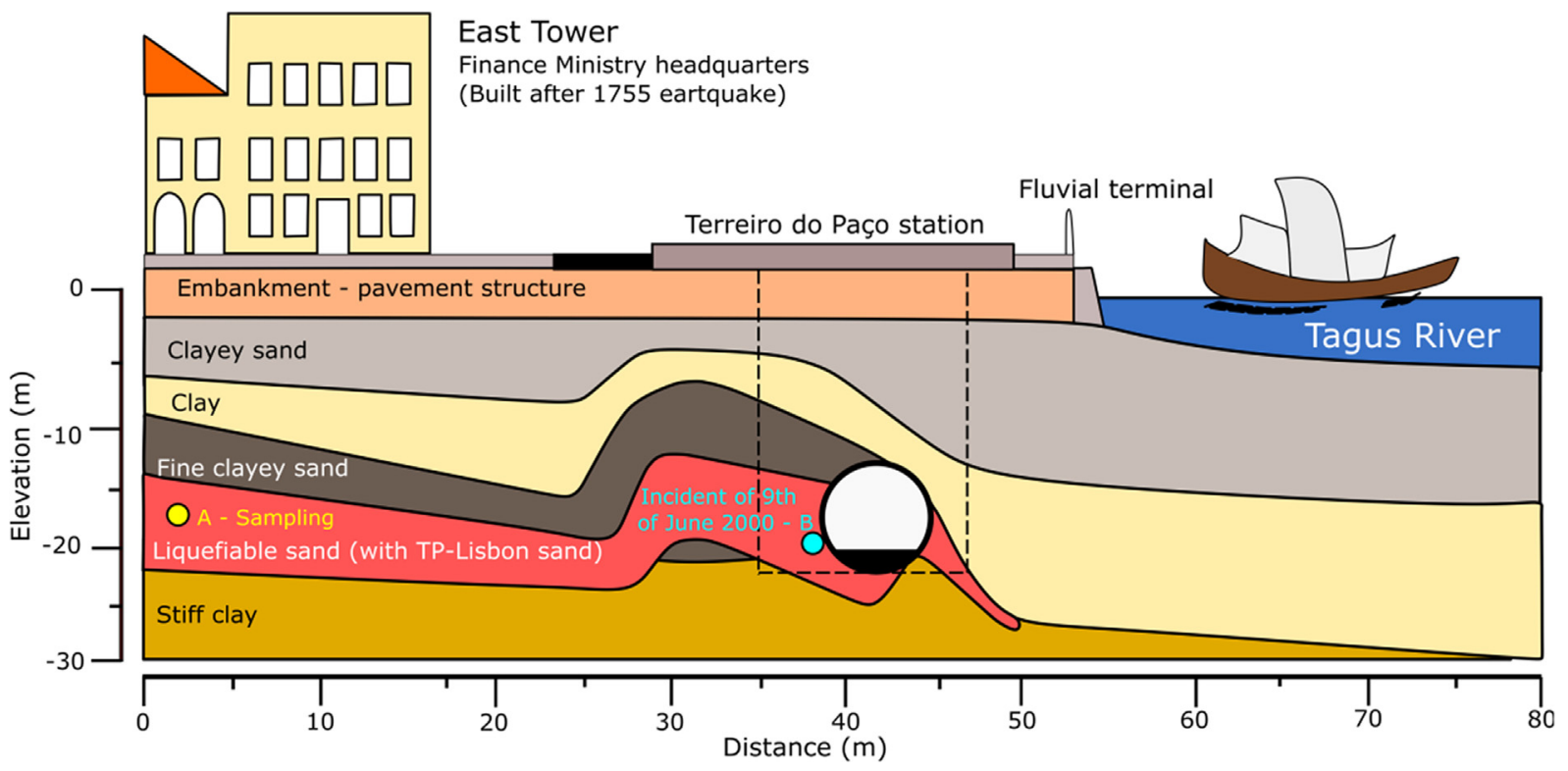

Fig. 1. Lithological profile Praça do Comércio (adapted from Salgado, 2009, 2019). 


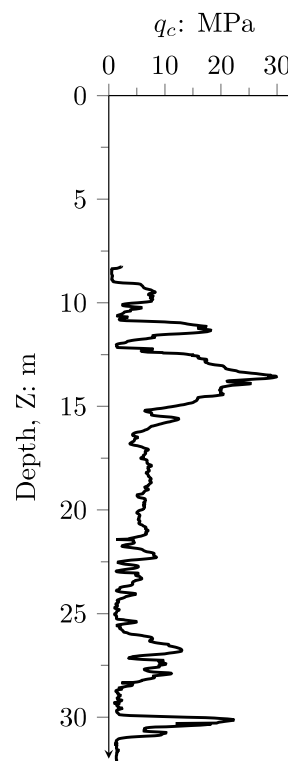

a)
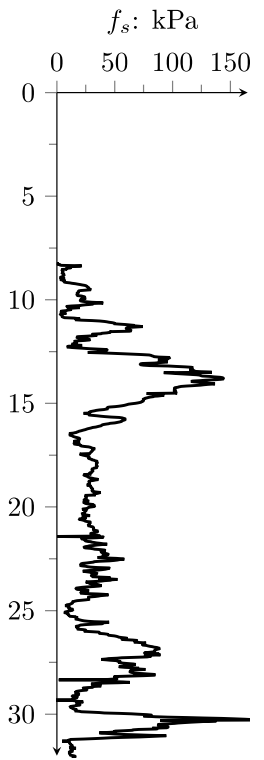

b)
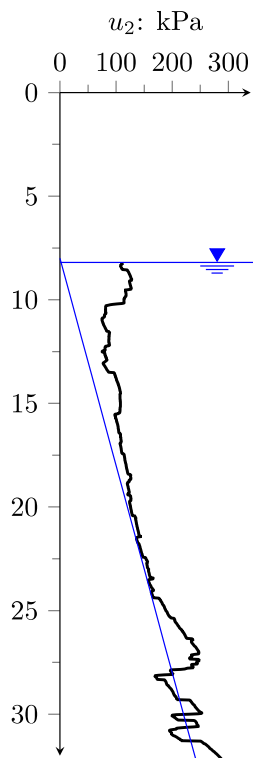

c)
Fig. 2. Primary data of CPTu: (a) cone tip resistance; (b) sleeve friction; (c) pore-water pressure generated during the cone penetration.

important projects of infrastructure in Portugal. However, some of them involved serious incidents, such as the collapse on 9th of June 2000 during the construction of a deep station for the new line of Lisbon blue line tunnel of 'Metropolitano de Lisboa' (point B in Fig. 1). This incident caused settlements on the surface, which affect some Pombalino buildings that surround one of the most relevant and historical sites in Lisbon (Salgado, 2009). Detailed work carried out by Salgado (2019) indicates that this incident was induced by flow liquefaction triggered during the application of the jet grouting technique for stabilising the alluvial soils (around the underground tunnel) before to prepare the retaining structure that supports the new deep station.

A geotechnical site characterisation of Praça do Comércio was performed by a piezocone penetration test $(\mathrm{CPTu})$. Fig. 2 presents the primary data of the CPTu tests, cone tip resistance $\left(q_{c}\right)$, sleeve friction $\left(f_{s}\right)$ and pore-water pressure generated during the cone penetration $\left(u_{2}\right)$. In situ testing started at $8 \mathrm{~m}$ depth due to the presence of remains from the old palace and compacted materials, used for the embankment and the pavement structure surrounding Praça do Comércio site, as showed in Fig. 1.

Primary data were analysed in terms of the soil behaviour type (SBT) methodology proposed by Robertson (2009). From the SBT analysis, a thick layer composed of clean sand to silty sand and silty sand to sandy silt was identified between 13 and $23 \mathrm{~m}$ depth (see Fig. 3). The soils composed such a layer are the focus of this study -corresponding to TP-Lisbon sand. Besides, SBT analysis did not reveal the presence of cementation in such a layer. This affirmation is supported by the recent earthquake-induced liquefaction events in the Lisbon area (1755 and 1909 earthquakes), which likely eliminated the natural bounding

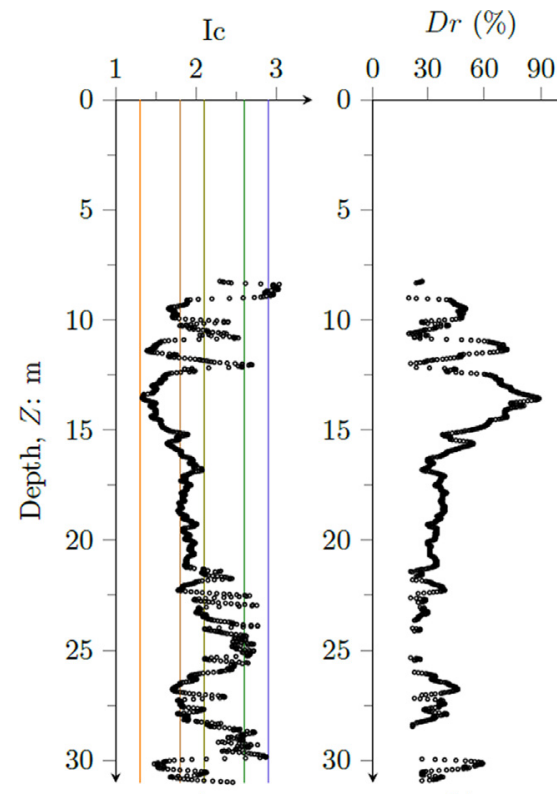

a)

b)

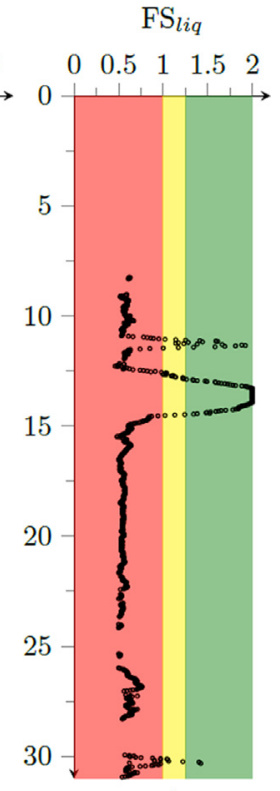

c)
Fig. 3. Interpreted CPTu profiles: (a) soil behaviour index (b) relative density; (c) factor of safety against liquefaction.

after experienced these phenomena. On the other hand, a relative density $(D r)$ profile was estimated using the correlation proposed by Robertson (2009). Such an estimation was conducted for the layers that exhibited Ic $<2.6$. Moreover, an assessment of liquefaction susceptibility based on $\mathrm{CPTu}$ results was carried out using the simplified procedure proposed by Boulanger and Idriss (2014), which relates the cyclic resistance ratio (CRR) with the cyclic stress ratio (CSR) to estimate the factor of safety against liquefaction $\left(\mathrm{FS}_{\text {liq }}\right)$.

Fig. 3 shows the interpreted profiles of the CPTu at Praça do Comércio site. From the interpreted profiles, it can be observed that the thick sandy layer composing TP-Lisbon sand has two sections. The first section covers a very dense sand ( $D r>70 \%)$ from 13 to $15 \mathrm{~m}$ depth, which is not susceptible to trigger liquefaction. The second section corresponds to a loose sand $(30 \%<D r<50 \%)$ with a high susceptibility to soil liquefaction. Therefore, in situ characterisation showed that TP-Lisbon sand is a liquefiable soil susceptible to trigger liquefaction in case occurrence of an earthquake with $\mathrm{M}>7.5$.

\subsection{Sample preparation}

The sand studied in this paper was obtained by Keller Groundbau GmbH Company using a rotary probe attached to a Shelby sampler device able to retrieve integral samples of $110 \mathrm{~mm}$ diameter in the vertical direction. The samples were collected between 13 and $23 \mathrm{~m}$ depth in a site investigation point located in the Praça do Comércio at the coordinates $38^{\circ} 42^{\prime} 26.61^{\prime} \mathrm{N}-9^{\circ} 8^{\prime} 13.37^{\prime \prime} \mathrm{W}$ (point A in Fig. 1). For this study, a series of soil specimens were prepared using mainly the dry pluviation method, and a few samples 
were prepared using the moist tamping method. The dry pluviation method ensures reasonably homogeneous specimens with an initial soil fabric that is believed to be similar to the one encountered in alluvial soil deposits (Miranda et al., 2020; Molina-Gómez et al., 2020). The specimens prepared through the moist tamping method allowed evaluating differences concerning the initial soil fabric effects on the mechanical behaviour of TP-Lisbon sand.

The soil remoulding using dry pluviation comprised the soil deposition at constant fall height using a funnel. This procedure is done by rotating and lifting up the funnel with dry soil (Yamashita et al., 2009). During the process, the funnel is risen at constant rate to maintain a constant drop-height throughout the specimen remoulding. The dry pluviation method provides soil specimens with uniform density in the range of very loose to dense ( $\mathrm{Dr}$ of about $25 \%-75 \%$ ). On the other hand, the moist tamping method implemented in this study covered the compaction of six layers of soil using a water content of about $5 \%$. Furthermore, the soil compaction was carried out by applying the under compaction method (Ladd, 1977). The undercompaction method reduces the segregation of soil grains and allows obtaining uniform layers with the same density. In this study, a percent undercompaction equal to $2 \%$ was adopted.

\subsection{Testing procedures}

The experimental plan in the laboratory was carried out combining index classification tests with advanced testing. The advanced testing included: $(a)$ one-dimensional consolidation tests; $(b)$ monotonic triaxial tests; and $(c)$ bender element tests. Soil specimens were tested under dry and saturated conditions. The saturated specimens were used for all advanced testing program, while the dry specimens allowed contrasting the compressibility and dynamic properties of TP-Lisbon sand, as discussed below.

The one-dimensional consolidation tests were carried out using front-loading oedometer frames. These tests included the testing of soil samples under dry and full saturation conditions. During one-dimensional consolidation tests, the full saturation of the soil was reached by inundating the oedometer cell with deaired water and waiting for $12 \mathrm{~h}$. Moreover, a series of loading and unloading steps were implemented to assess the compressibility of TPLisbon sand by applying a series of vertical effective stress to estimate its compressibility and possible location of the one-dimensional normal consolidation line (1D-NCL) in the $e: \log p^{\prime}$ invariant space.

The use of saturated specimens had a special focus on the estimation of critical state locus (CSL). To saturate the specimens for triaxial testing the procedure suggested by Soares and Viana da Fonseca (2016) was applied. Saturation procedure incorporated two phases: $(i)$ percolation with $1.5 \mathrm{~L}$ of $\mathrm{CO}_{2}$ and $400 \mathrm{ml}$ of de-aired water gently flushing; and (ii) the application of a back-pressure increment at a constant effective stress of $10 \mathrm{kPa}$ until reach
$300 \mathrm{kPa}$. The specimens were only considered completely saturated when Skempton's B-value $>0.97$. This procedure allowed achieving a full saturation condition with B-values higher than 0.98 . Such a range of values was selected based on the systematic comparison performed by Soares \& Viana da Fonseca (2016) between Skempton's B-value and compression wave velocity. By experimental evidence, these authors demonstrated that specimens with Bvalue $>0.97$ achieve compression wave velocities higher than its corresponding value in the water -that is, values higher than $1482 \mathrm{~m} / \mathrm{s}$ (Santamarina et al., 2001).

In addition, for triaxial testing, two equipment configurations were used. The first configuration corresponds to triaxial cells with lubricated end platens and an embedded connection piston into the top-cap. The second configuration is a Bishop-Wesley type stress-path triaxial cell equipped piezoelectric ceramic instruments. The use of lubricated end platens allows reducing the influence of platen restraint on stresses in the soil sample during triaxial testing, which induces uniform radial strains and helps to keep the cylindrical shape of the specimen at large axial strain levels. The embedded connection piston allows to significantly reducing 'tilting' of the top cap during all phases of triaxial testing, providing more reliable test results for assessing shear-strain behaviour and CSL of soils (Reid et al., 2020). On the other hand, the piezoelectric ceramic instruments allow measuring the seismic wave velocities in the soil sample by bender element testing.

All soil specimens were isotropically consolidated at different confining effective stress $\left(p_{0}^{\prime}\right)$ and sheared at $0.025 \mathrm{~mm} / \mathrm{min}$. The adopted axial strain velocity is compatible with the rate of excess pore pressure dissipation in the specimen. To ensure the accuracy of the results, data have been corrected for membrane restraint using the method as indicated in the standard procedure ISO/TS 17892-9 (ISO, 2004). At the end of the shear stage, all specimens tested in the triaxial cell with lubricated end platens were frozen to ensure a very accurate measurement of the final void ratio of the soil after testing, as observed by Soares \& Viana da Fonseca (2016); Reid et al. (2020). For the case of the tests conducted in the triaxial equipment equipped piezoelectric ceramic instruments, the specimens were carefully removed from the cell, avoiding possible loss of soil particles and water, as suggested by Verdugo \& Ishihara (1996). This procedure allows a correct measurement of the final void ratio after testing based on the final water content (Murthy et al., 2007). The freezing was not used during the tests conducted in the triaxial apparatus with $\mathrm{BE}$ to avoid damages in the piezoelectric ceramic instruments.

Bender element (BE) tests were conducted to assess the stress-dependency of the seismic wave velocities -shear and compression wave velocities- of TP-Lisbon sand. The compression wave velocity $(V p)$ measurements had a particular focus on dry specimens, while the shear wave velocity $(V s)$ measurements were compared in both dry and saturated specimens. For BE testing, a single 
sinusoidal pulse was used as an input signal to excite the BE transmitter. The wave propagation travel time $\left(t_{t}\right)$ between the distance of the elements $\left(L_{t t}\right)$ was obtained using the first arrival method (Lee \& Santamarina, 2005).

\section{Intrinsic properties and state of TP-Lisbon sand}

A series of particle-size analyses using the sieve method ASTM D6913 was carried out. Hence, integral soil samples collected between 13 and $23 \mathrm{~m}$ depth were tested to measure the grain size distribution of the sandy soil composing the thick liquefiable layer at Praça do Comércio (point $\mathbf{A}$ in Fig. 1). These tests were conducted for samples located at each meter depth. Due to the low variability of grain size distributions (GSD) of the studied sandy soils, these samples were blended. The GSD of blended soil provides a good representation of the range of grain sizes in the field. Fig. 4 presents the grain size distribution of the collected soil between 13 and $23 \mathrm{~m}$ depth and the blended material -giving to TP-Lisbon sand.

The mineralogy of TP-Lisbon sand is 78\% Quartz, 8\% Orthoclase $8 \%$, Muscovite and 6\% Albite. Table 2 summarises the physical properties measured in the laboratory, including the specific gravity of solid particles (Gs), mean diameter $\left(\mathrm{D}_{50}\right)$, maximum and minimum void ratio $\left(e_{\max }\right.$ and $e_{\text {min }}$ ). Moreover, Table 2 includes two parameters of the grain size distribution of TP-Lisbon sand, namely the coefficient of curvature $(C z)$ and coefficient of uniformity $(C u)$, as well as the mean diameter $\left(D_{50}\right)$. According to the unified soil classification system (USCS), TP-Lisbon sand was classified as a poorly graded sand (SP), with low values of $C u$ and $C z$, which indicate a uniform particle size distribution.

Due to the interest in studying the effect of soil package on the mechanical behaviour of TP-Lisbon sand, $\mathrm{e}_{\max }$ and $\mathrm{e}_{\min }$ were estimated by the ASTM and Japanese Geotechnical Society (JGS) standard procedures (D4253; D4254;

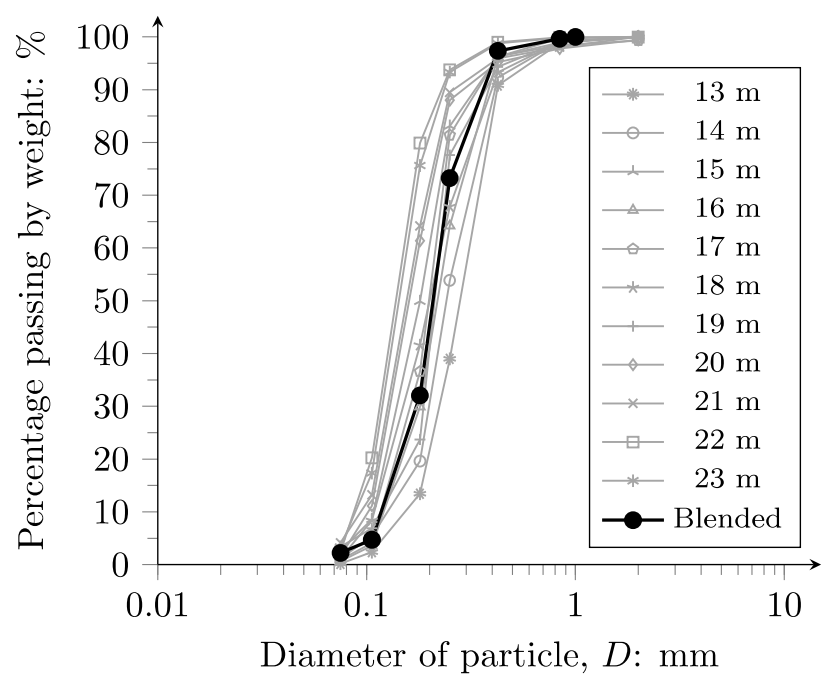

Fig. 4. Grain size distributions of sandy soils beneath Praça do Comércio and TP-Lisbon sand.
Table 2

Physical properties of TP-Lisbon sand.

\begin{tabular}{ll}
\hline Parameter & Value \\
\hline$G s$ & 2.66 \\
$e_{\max }$ & $1.01^{*} ; 1.01^{+}$ \\
$e_{\min }$ & $0.63^{*} ; 0.64^{+}$ \\
$e_{\max }-e_{\min }$ & $0.38^{*} ; 0.39^{+}$ \\
$C z$ & 1.13 \\
$C u$ & 1.69 \\
$D_{50}(\mathrm{~mm})$ & 0.21 \\
Fines content $(\%)$ & 2.21 \\
\hline
\end{tabular}

Note: ${ }^{*}$ ASTM method; ${ }^{+}$JGS method.

JGS 0161). For measuring $e_{\max }$, these standard procedures address the air pluviation technique using a funnel located as close as possible to the soil surface to achieve its loosest condition. The main differences between these procedures relate to using moulds with different dimensions, $2830 \mathrm{~cm}^{3}$ for the ASTM procedure and $113 \mathrm{~cm}^{3}$ for the JGS procedure. For measuring $\mathrm{e}_{\min }$, ASTM and JGS procedures use the same moulds before mentioned but involve a vertical vibrating table and the application of horizontal blows, respectively. Since the applied energy per volume, $e_{\min }$ values obtained from the JGS method yields slightly higher values than $e_{\min }$ values obtained from the ASTM (Lunne et al., 2019). Non-significant differences resulted by using both standard procedures for $e_{\max }$ and $e_{\min }$. The void ratio range $\left(e_{\max }-e_{\min }\right)$ agree with the values claimed by Ishihara et al. (2016) for clean sands. The results obtained through the ASTM methods will be used for further comparisons since these tests are the most common in geotechnical laboratories worldwide.

The particle shape has a strong influence on the extreme void ratios and various mechanical properties like the small-strain stiffness sand shear strength of sands (Sarkar et al., 2020). The shape of particles was assessed through extensive morphological imaging analysis, including samples with more than 15,000 sand particles. The equipment used in this research was a Morphologi G3-ID, produced by Malvern Panalytical Company, which can measure individual particles with sizes between $1.3 \mu \mathrm{m}$ and $1.0 \mathrm{~mm}$. This equipment can identify the length, width, perimeter, area and elongation of the particles. A macro photograph displaying the particles of TP-Lisbon sand is shown in Fig. 5.a. Based on macro photographs, the particle shape parameters were also estimated using a MATLAB algorithm implemented by Zheng \& Hryciw (2015). The procedure involved a careful observation of individual grains robust using numerical methods based on computational geometry to estimate the traditional values from twodimensional images using the binary form of particles, as shown in Fig. 5.b.

The computational algorithm used in this study assessed about 1000 random particles. The particle shape was defined by the mean values of the convexity $(C x)$, circularity $(C i)$, sphericity $(S)$, roundness $(R)$ and regularity $(\rho)$. Fig. 6 presents the definition of these morphological 


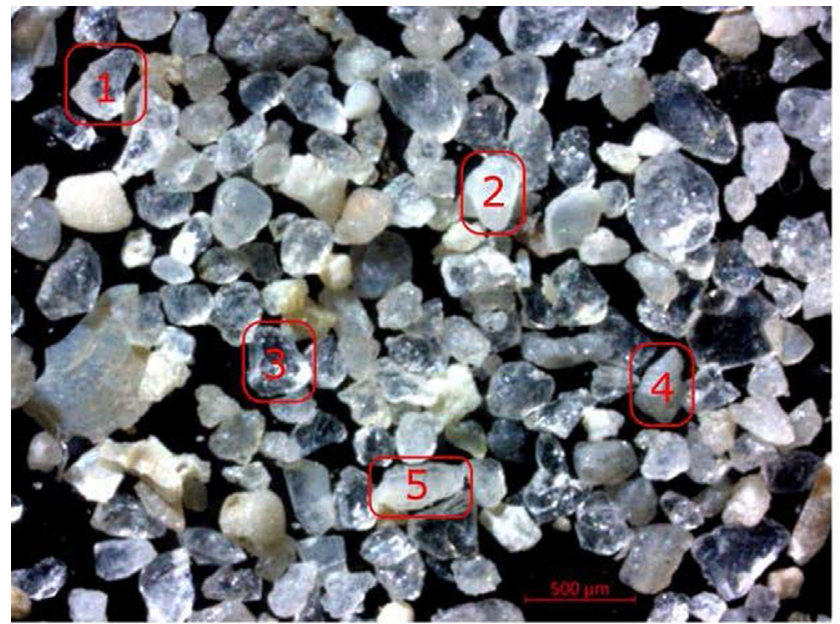

a)

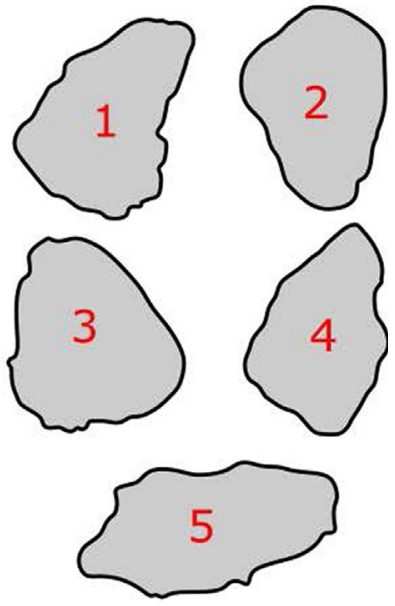

b)

Fig. 5. Particles of TP-Lisbon sand: (a) photograph of the particles taken with an optical microscope; (b) binary images of selected particles.

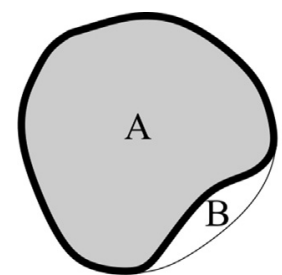

a)

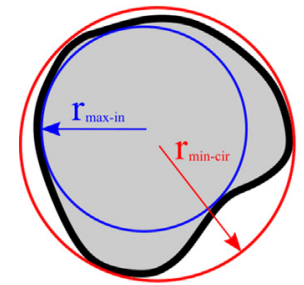

c)

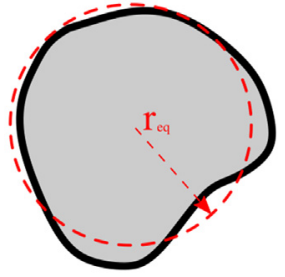

b)

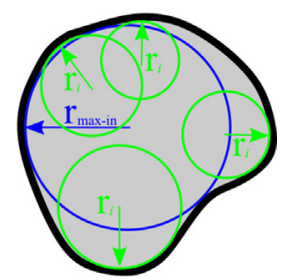

d)
Fig. 6. Graphical definitions of particle shape parameters: (a) convexity, (b) circularity; (c) sphericity; (d) roundness.

parameters. $C x$ is the ratio between the particle area $(A)$ with the area of the particle when any convexities inside its perimeter are filled $(A+B)$, providing a measure of the compactness of the particle (Altuhafi et al., 2016). $C i$ is a function of a projected area and perimeter of the particle ( $A_{p}$ and $P_{p}$ ). Both $A_{p}$ and $P_{p}$ are computed by estimating the radius $\left(\mathrm{r}_{\mathrm{eq}}\right)$ of a circle with an equivalent area of the analysed particle (Lashkari et al., 2020). $S$ quantifies how close a particle's largest projected area is to a perfect circle (Zheng \& Hryciw, 2015). Therefore, the $S$ computation covers the ratio of the radius of the maximum inscribed circle $\left(\mathrm{r}_{\text {max-in }}\right)$ with the radius of the minimums circumscribed circle $\left(\mathrm{r}_{\text {min-cir }}\right)$. $R$ describes the sharpness of particle's corners $(N)$ by estimating the ratio of the average radius of curvature of such corners $\left(\mathrm{r}_{i}\right)$ to $\mathrm{r}_{\text {max-in }}$ (Zheng et al., 2017). $\rho$ is the average value between $S$ and $R$ (Cho et al., 2006; Yang \& Luo, 2015).
Fig. 7 illustrates the procedure for assessing the particle shape parameters. Table 3 summarises the results of the particle shape analysis. Results showed that the particles of TP-Lisbon sand are predominately subangular according to Shape-Angularity Group Indicator $(\mathrm{SAGI}=11.76$ ) proposed by Altuhafi et al. (2016). This classification indicated that the particles composing TP-Lisbon sand have a morphology similar to well-characterised silica natural sands, namely Ticino and Toyoura sands, as reported by Altuhafi et al. (2016).

\section{Compressibility of TP-Lisbon sand}

The compressibility of TP-Lisbon sand was investigated by a series of one-dimensional oedometer compression tests by apparatuses capable of testing specimens of $50 \mathrm{~mm}$ and $70 \mathrm{~mm}$ diameter. The tests were carried out in four specimens prepared using the dry pluviation and moist tamping methods. All the specimens were prepared for an initial void ratio value close to the $e_{\max }$ (indicated in Table 2). Moreover, the tests were conducted under dry and full saturation conditions, corresponding to one dry test with a specimen prepared using the dry pluviation method and three saturated tests with specimens prepared using both methods. Of these three saturated tests, two were conducted using soil specimens $50 \mathrm{~mm}$ diameter, and one was performed using a specimen $70 \mathrm{~mm}$ diameter. The samples reached a high degree of saturation by inundating the oedometer cell with deaired water and waiting for $12 \mathrm{~h}$. The maximum applied vertical effective stress $\left(\sigma_{\mathrm{v}}^{\prime}\right)$ in onedimensional oedometer compression tests was reached at $6400 \mathrm{kPa}$ in the specimens of $50 \mathrm{~mm}$ diameter. Fig. 8 presents the compressibility curves obtained from onedimensional compression tests. Table 4 details the onedimensional tests and summarises the compressibility parameters obtained from the one-dimensional consolidation curves for the different initial void ratios and preparation methods. 


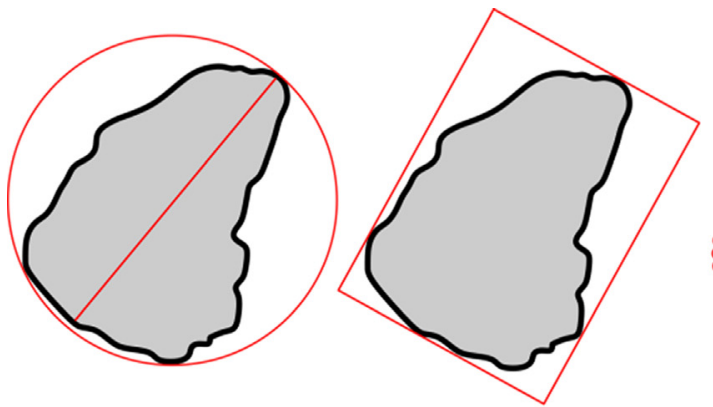

a)

b)

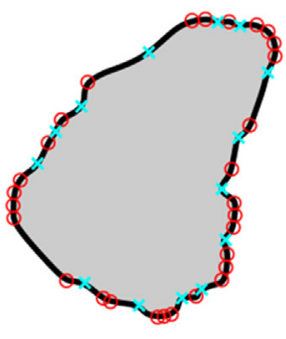

c)

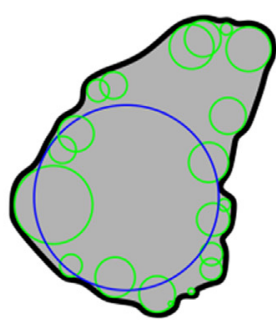

d)

Fig. 7. Example of the analysis of particle shape -particle 1 of Fig. 5: (a) diameter sphericity, (b) width to length ratio sphericity; (c) identification of particle corners; (d) circle corner fitting of the particle.

Table 3

Shape parameters of TP-Lisbon sand.

\begin{tabular}{|c|c|c|}
\hline Particle shape parameter & Mathematical definition & Value \\
\hline Convexity & $C x=\frac{A}{A+B_{A}}$ & 0.95 \\
\hline Circularity & $C i=\frac{2+\sqrt{t} A_{p}}{C}$ & 0.88 \\
\hline Roundness & $R=\frac{\sum_{i=1}^{P_{p}}\left(r_{i} / N\right)}{r_{\text {ins }}}$ & 0.38 \\
\hline Sphericity & $S=\frac{r_{\max }-i n}{r_{\text {in }}}$ & 0.72 \\
\hline Regularity & $\rho=\frac{S_{+i n} \bar{R}}{2}$ & 0.55 \\
\hline
\end{tabular}

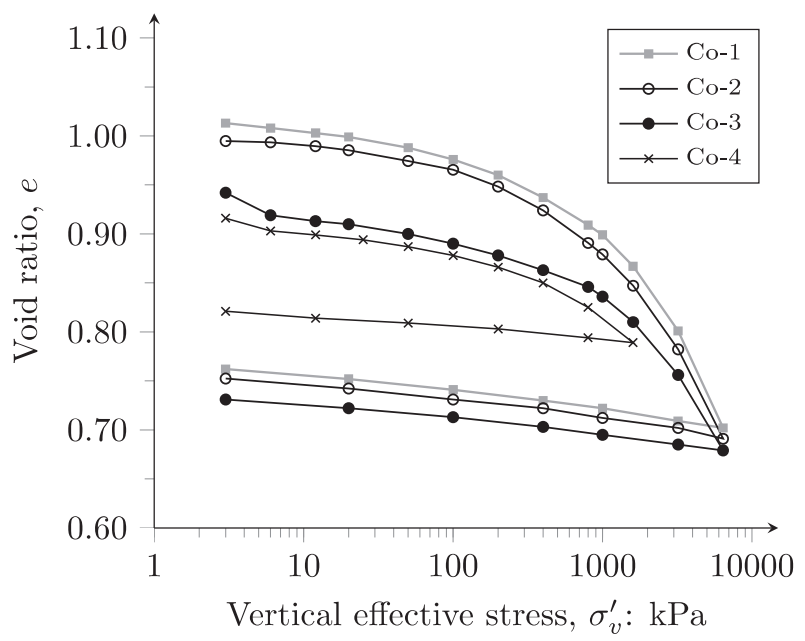

Fig. 8. One-dimensional compression behaviour of TP-Lisbon sand.

Compressibility curves revealed a very similar shape between the specimens prepared by dry pluviation and moist tamping. Besides, these curves indicated that the one-dimensional compression behaviour of TP-Lisbon sand is similar under dry and saturated conditions for close initial void ratios, even when using different methods of preparation. A comparison between the curves of the specimens of $50 \mathrm{~mm}$ and $70 \mathrm{~mm}$ diameter showed that there is not an important effect of the specimen size on the oedometer compressibility behaviour of TP-Lisbon sand. On the other hand, Fig. 8 shows that the curves of the samples prepared using the dry pluviation method and tested under saturated conditions presented a 'collapse' after the first load stage.

A grain size distribution analysis was carried out after finishing the test of specimen $70 \mathrm{~mm}$ diameter to assess the particle crushing and its influence on the compressibility behaviour of TP-Lisbon sand. GSD was not assessed for the specimens of $50 \mathrm{~mm}$ due to the minimum amount of material established in ASTM D422 standard. The test results revealed that the GSD does not change after testing, showing that there is not crushing of particles of TP-Lisbon sand when applying $\sigma_{\mathrm{v}}^{\prime}$ lower than $1600 \mathrm{kPa}$. Notwithstanding, Fig. 8 shows that for $\sigma_{\mathrm{v}}^{\prime}$ between $1600 \mathrm{kPa}$ and $6400 \mathrm{kPa}$ the slope of curves increases, that is, an indication of crushing onset of particles in such range of stresses. Therefore, results obtained in the $\sigma^{\prime}{ }_{\mathrm{v}}$ range between $6 \mathrm{kPa}$ and $1600 \mathrm{kPa}$ was considered to interpret the compressibility curves.

Values presented in Table 4 indicate that there are no significant differences between the results of the four oedometer tests. Moreover, the results of $C c$ values reported in Table 4 agree with the compression parameters observed by Mesri \& Vardhanabhuti (2009), which vary from 0.03 to 0.63 for $\sigma_{\mathrm{v}}^{\prime}$ between 1000 and $10000 \mathrm{kPa}$ in very loose conditions. This range is suitable for angular

Table 4

Compressibility parameters of TP-Lisbon sand.

\begin{tabular}{|c|c|c|c|c|c|c|c|c|}
\hline Test name & Method of preparation & Specimen diameter $(\mathrm{mm})$ & Test condition & $e_{0}$ & $C c$ & $\mathrm{Cr}$ & $\mathrm{Ce}$ & $\overline{C r} / C c$ \\
\hline Co-1 & MT & 50 & Saturated & 1.01 & 0.1266 & 0.0220 & 0.0203 & 0.1738 \\
\hline $\mathrm{Co}-2$ & $\mathrm{Pv}$ & 50 & Dry & 0.99 & 0.1277 & 0.0223 & 0.0217 & 0.1746 \\
\hline $\mathrm{Co}-3$ & Pv & 50 & Saturated & 0.94 & 0.1244 & 0.0212 & 0.0199 & 0.1704 \\
\hline
\end{tabular}

Note: MT is moist tamping; $\mathrm{Pv}$ is dry pluviation; $e_{0}$ is initial void ratio; $C c$ is compression index; $C r$ is recompression index; $C e$ is expansion index. 
to subangular quartz sands; such as Mol sand, which is a sandy soil with similar intrinsic properties to TP-Lisbon sand $\left(C u=1.75\right.$ and $\left.D_{50}=0.20 \mathrm{~mm}\right)$.

Moreover, the compressibility of TP-Lisbon sand was explored through isotropic triaxial tests. Such tests will be further discussed in the following sections of this paper. For silica sands, the intrinsic consolidation line (ICL) is non-unique, and multiple ICLs exist depending on the initial void ratio, $e_{0}$ (Jefferies \& Been, 2000). However, in many cases, these ICLs converge to a single line known as limiting compression line (LCL), which becomes apparent at a high-stress level and before the onset of grain crushing (Pestana \& Whittle, 1995). Fig. 9 shows a series of end consolidation points obtained in the triaxial tests. Besides, Fig. 9 presents three characteristic isotropic consolidation paths obtained for $e_{0}$ of about $0.96,0.92$ and 0.86 , which end at 200,500 and $800 \mathrm{kPa}$, respectively. These isotropic consolidation paths well-represent the ICL of the referred $e_{0}$, as confirmed by the end consolidation points obtained for similar initial states.

From isotropic consolidation paths, a possible limiting compression line (LCL) was inferred for TP-Lisbon sand. LCL was estimated by considering LCL the endpoint of three isotropic consolidation paths. In Fig. 9, it can be observed that the LCL line is almost parallel to a 1DNCL deduced from the one-dimensional compressibility. The parallelism between such lines is consistent regarding the behaviour observed in granular materials by $\mathrm{Li}$ et al. (2018) and Qadimi \& Coop (2007). 1D-NCL was obtained from the compression curves of $\mathrm{Co}-2$ test within the range $400 \mathrm{kPa}$ and $1600 \mathrm{kPa}$ - according to the procedure proposed by Carrera et al. (2011). This range was selected because at these stresses TP-Lisbon sand does not experience crushing of particles.

The definition of ICLs for $e_{0}$ values close to $e_{\max }$ $\left(e_{0}>0.96\right)$ was not possible due to the volume reduction of the specimens during de-aired water flushing after $\mathrm{CO}_{2}$ percolation, as also observed in the assessment of the

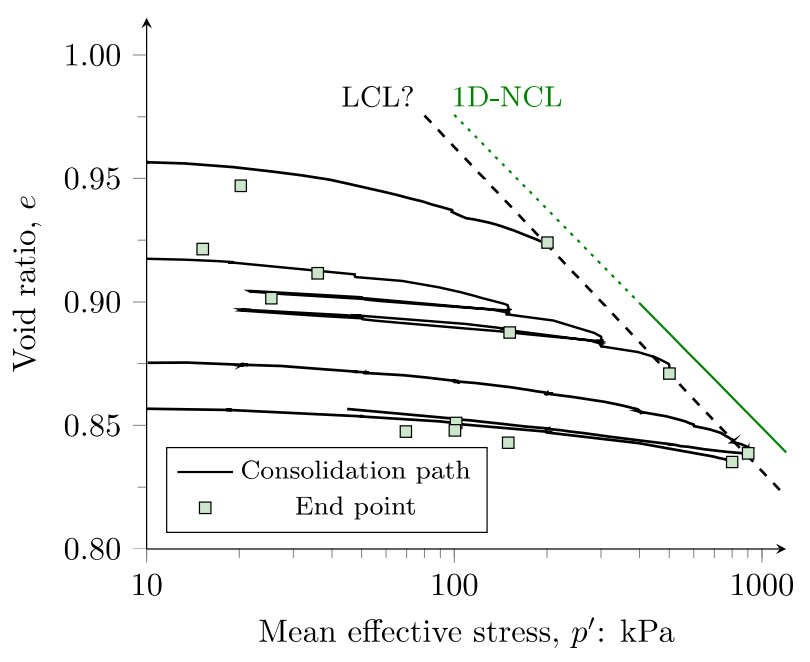

Fig. 9. Isotropic consolidation of TP-Lisbon sand. one-dimensional compression tests (see Fig. 8). Similar behaviour was described by Been \& Jefferies (2004). These authors reported a significant volume reduction during the saturation of very loose sandy samples. Therefore, soil collapse during water flushing did not allow obtaining soil specimens with a void ratio higher than 0.96 (or $D r<0.14)$ at the end of the consolidation phase. Although the convergence of some ICLs to a single line, additional triaxial tests involving high-stress levels are required to confirm the LCL inferred in this study.

\section{Stress-strain behaviour and critical state in TP-Lisbon sand}

A total of 19 monotonic triaxial compression tests were conducted on loose and medium dense specimens $(D r<63 \%)$. The experimental plan included 14 tests under drained conditions and 5 tests under undrained conditions. These tests were carried out by combing the equipment configurations and the two methods for specimen preparation described in Section 2.3. Table 5 summarises the details and final results of triaxial tests. Fig. 10 presents the results of the triaxial tests carried out for the characterisation of TP-Lisbon sand. From Fig. 10, it can be observed that the stress-strain curves have a similar shape for both drained and undrained tests. Most of the tests were sheared to axial strains up to $25 \%$ to reach the critical state, except for TxU15-300 test that concluded close to $20 \%$ axial strain because the triaxial apparatus reached its maximum displacement.

For the drained tests, the peak deviatoric stress occurs at $7 \%-15 \%$ axial strain, a sign of the predominant dilative state of soil specimens, except for TxD11-200 and TxD12-500 tests that presented a contractive behaviour. All curves of drained tests do not show strain-softening. This effect is a result of the top cap-loading ram connection, which leads to a more uniform sample shearing behaviour (Reid et al., 2020). Only TxD8-150, with an initial relative density of $62 \%$, test presented a clear reduction in the deviatoric stress after $12 \%$ axial strain, that is, there is not strain-localisation during shear. The stabilisation in the change of volumetric strains is reached earlier in the specimens with contractive behaviour or positive volumetric strains (e.g. TxD11-200 and TxD12-500). The specimens with dilative behaviour show an expected positive change of volumetric strain before dilation, which initiated at $4 \%$ of axial strain. The volumetric strains are all reasonably stable at the end of the tests, meaning that the critical state has been reached or nearly reached. Notwithstanding, the critical state condition was confirmed by assessing the volumetric strain increment and the rate of change in deviatoric strain increment rates, as discussed below.

On the other hand, for undrained tests, the phase transformation occurs within the range of $1-2 \%$ axial strain. This transformation generates an increment in deviatoric stress and a reduction in the pore pressure, increasing the shear strength of the soil. In addition, once the initial peak 
Table 5

Details of triaxial tests.

\begin{tabular}{|c|c|c|c|c|c|c|c|c|c|}
\hline \multirow[t]{3}{*}{ Test name } & \multirow{3}{*}{$\begin{array}{l}\text { Triaxial } \\
\text { cell }\end{array}$} & \multirow{3}{*}{$\begin{array}{l}\text { Method of } \\
\text { preparation }\end{array}$} & \multirow{3}{*}{$\begin{array}{l}\text { Test } \\
\text { condition }\end{array}$} & \multicolumn{3}{|l|}{ After consolidation } & \multicolumn{3}{|l|}{ End of test } \\
\hline & & & & \multirow{2}{*}{$\begin{array}{l}\text { Mean effective stress, } \\
p_{0}^{\prime}: \mathrm{kPa}\end{array}$} & \multirow{2}{*}{$\begin{array}{l}\text { Void ratio } \\
e\end{array}$} & \multirow{2}{*}{$\begin{array}{l}\text { Relative density, } \\
\operatorname{Dr}: \%\end{array}$} & & & \\
\hline & & & & & & & $\begin{array}{l}\text { Deviatoric } \\
\text { stress, } q_{\mathrm{cs}}: \mathrm{kPa}\end{array}$ & $\begin{array}{l}\text { Mean effective stress, } \\
p_{\text {cs }}^{\prime}: \mathrm{kPa}\end{array}$ & $\begin{array}{l}\text { Void ratio, } \\
e_{c s}\end{array}$ \\
\hline TxD1-10 & LEP & $\mathrm{Pv}$ & D & 10 & 0.9290 & 22 & 28 & 20 & 0.9681 \\
\hline TxD2-15 & LEP & $\mathrm{Pv}$ & D & 15 & 0.9214 & 24 & 37 & 28 & 0.9649 \\
\hline TxD3-20 & LEP & $\mathrm{Pv}$ & $\mathrm{D}$ & 20 & 0.9369 & 18 & 52 & 39 & 0.9620 \\
\hline TxD4-25 & LEP & $\mathrm{Pv}$ & $\mathrm{D}$ & 25 & 0.9015 & 29 & 62 & 47 & 0.9498 \\
\hline TxD5-35 & LEP & $\mathrm{Pv}$ & $\mathrm{D}$ & 35 & 0.9116 & 27 & 95 & 70 & 0.9386 \\
\hline TxD6-50 & LEP & $\mathrm{Pv}$ & $\mathrm{D}$ & 51 & 0.8349 & 49 & 143 & 100 & 0.9161 \\
\hline TxD7-50 & LEP & MT & D & 50 & 0.9232 & 19 & 121 & 87 & 0.9303 \\
\hline TxD8-70 & LEP & $\mathrm{Pv}$ & D & 70 & 0.8475 & 44 & 185 & 134 & 0.8998 \\
\hline TxD9-100 & LEP & $\mathrm{Pv}$ & D & 100 & 0.8495 & 43 & 273 & 192 & 0.8821 \\
\hline TxD10-150 & LEP & $\mathrm{Pv}$ & D & 149 & 0.7845 & 62 & 362 & 271 & 0.8631 \\
\hline TxD11-150 & LEP & MT & $\mathrm{D}$ & 151 & 0.8876 & 32 & 355 & 268 & 0.8765 \\
\hline TxD12-150 & $\mathrm{BE}$ & MT & $\mathrm{D}$ & 150 & 0.8430 & 45 & 320 & 257 & 0.8808 \\
\hline TxD13-200 & LEP & MT & $\mathrm{D}$ & 200 & 0.9240 & 23 & 487 & 362 & 0.8592 \\
\hline TxD14-500 & $\mathrm{BE}$ & $\mathrm{Pv}$ & $\mathrm{D}$ & 500 & 0.8710 & 38 & 1279 & 928 & 0.8060 \\
\hline TxU15-100 & LEP & $\mathrm{Pv}$ & $\mathrm{U}$ & 100 & 0.8511 & 43 & 460 & 350 & 0.8511 \\
\hline TxU16-150 & LEP & $\mathrm{Pv}$ & $\mathrm{U}$ & 150 & 0.8597 & 41 & 445 & 331 & 0.8597 \\
\hline TxU17-300 & $\mathrm{BE}$ & $\mathrm{Pv}$ & $\mathrm{U}$ & 300 & 0.8043 & 56 & * & * & $*$ \\
\hline TxU18-400 & LEP & $\mathrm{Pv}$ & $\mathrm{U}$ & 400 & 0.8293 & 49 & 638 & 496 & 0.8299 \\
\hline TxU19-500 & LEP & $\mathrm{Pv}$ & $\mathrm{U}$ & 500 & 0.8172 & 52 & 805 & 632 & 0.8172 \\
\hline
\end{tabular}

Note: LEP is lubricated end platen; BE is bender element; $\mathrm{D}$ is drained; $\mathrm{U}$ is undrained; * designates do not achieve the critical state. 


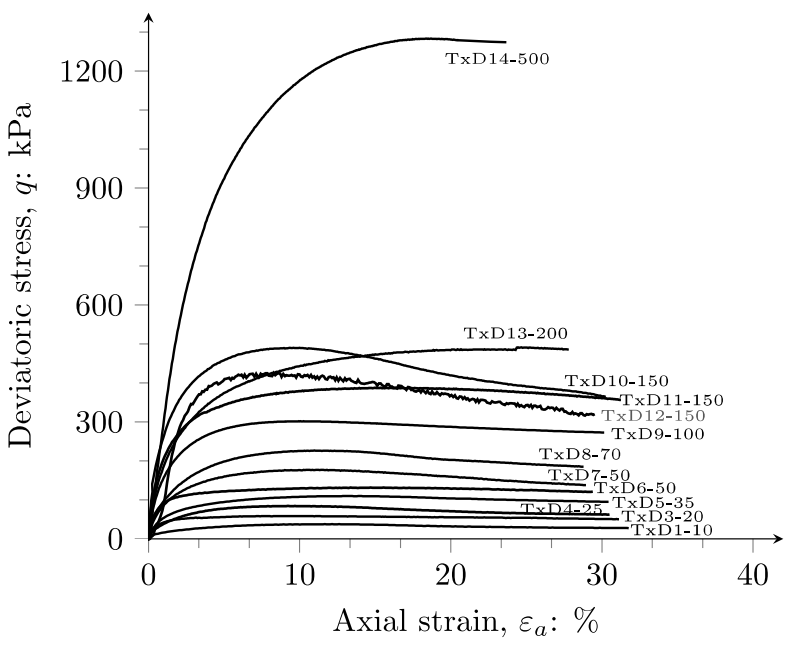

a)

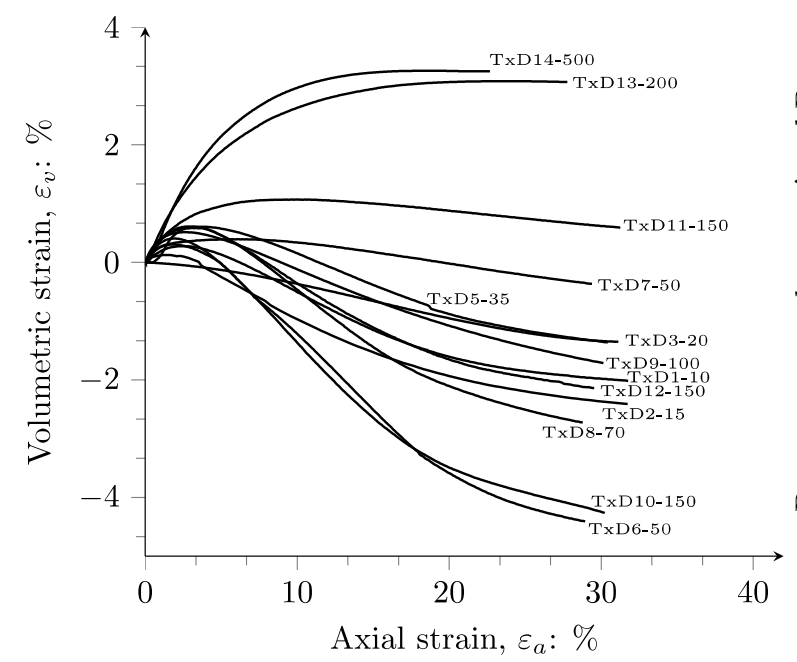

c)

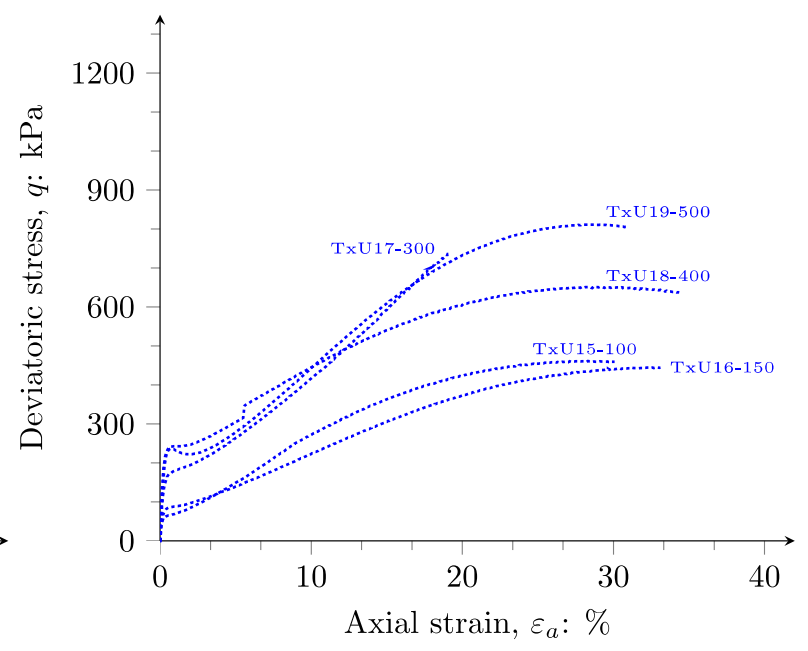

b)

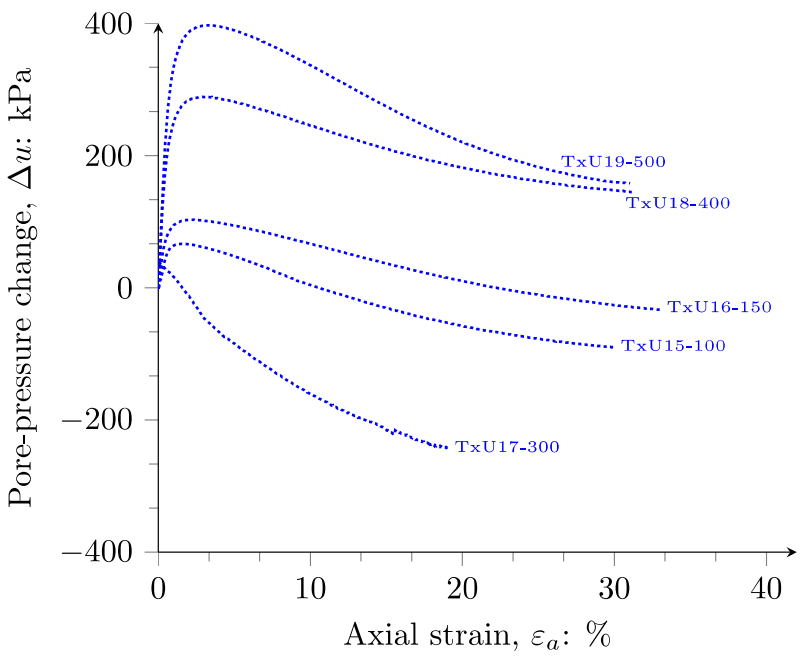

d)

Fig. 10. Triaxial test results on TP-Lisbon sand: (a) stress-strain behaviour in drained tests; (b) stress-strain behaviour in undrained tests; (c) change of volumetric strain in drained tests; (d) pore-pressure change in undrained tests.

deviatoric stress occurs, in about $25-27 \%$ axial strain, the stabilisation of the deviatoric stress and pore pressure keep constant, indicating that the soil has reached its critical state. Fig. 10 shows that the stress-strain and shearinduced pore pressure curves of the undrained test are parallel, even for Tx-300, which did not reach the critical state. Analogous evolution of shear-induced pore pressure was observed by Giretti \& Fioravante (2017) in alluvial liquefiable deposits.

The results of all drained and undrained triaxial tests considered to have reached the critical state were used to define the critical state parameters of TP-Lisbon sand. The critical state condition was confirmed by assessing the stress-dilatancy evolution in all tests, as is shown below in section 6. Fig. 11 presents the stress path on the $q: p^{\prime}$ invariant space derived from triaxial tests results. From Fig. 11, it can be observed that all endpoints define a unique critical state line (CSL) in the $q: p^{\prime}$ space, which is clearly represented by a straight line passing through the origin. The CSL projection $q: p^{\prime}$ space defines a strength parameter $M$ equal to 1.37 . Therefore, the angle of shearing resistance at large strains or in the critical state $\left(\phi_{\text {cs }}^{\prime}\right)$ of TP-Lisbon sand is $34^{\circ}$. Similar findings were reported by Gajo \& Wood (1999) for Hostun sand, which is a sandy soil with intrinsic properties very close to TPLisbon sand (e.g. $C u=1.80, e_{\max }=1.00$ and $e_{\min }=0.65$ ).

On the other hand, Fig. 11.b presents the undrained stress behaviour of TP-Lisbon sand under monotonic loading. This behaviour is interpreted by the phase transformation point and the undrained instability point. Murthy et al. (2007) define the phase transformation point as the point at which the sand response changes from contractive to dilative, and the undrained instability point as the point at which $q$ reaches a local and temporary maximum value. For TP-Lisbon sand, it was observed that the phase transformation point is close to the CSL, indicating soil dilatation once the soil reached a stable frictional state. Besides, although liquefaction was not triggered in undrained tests, 


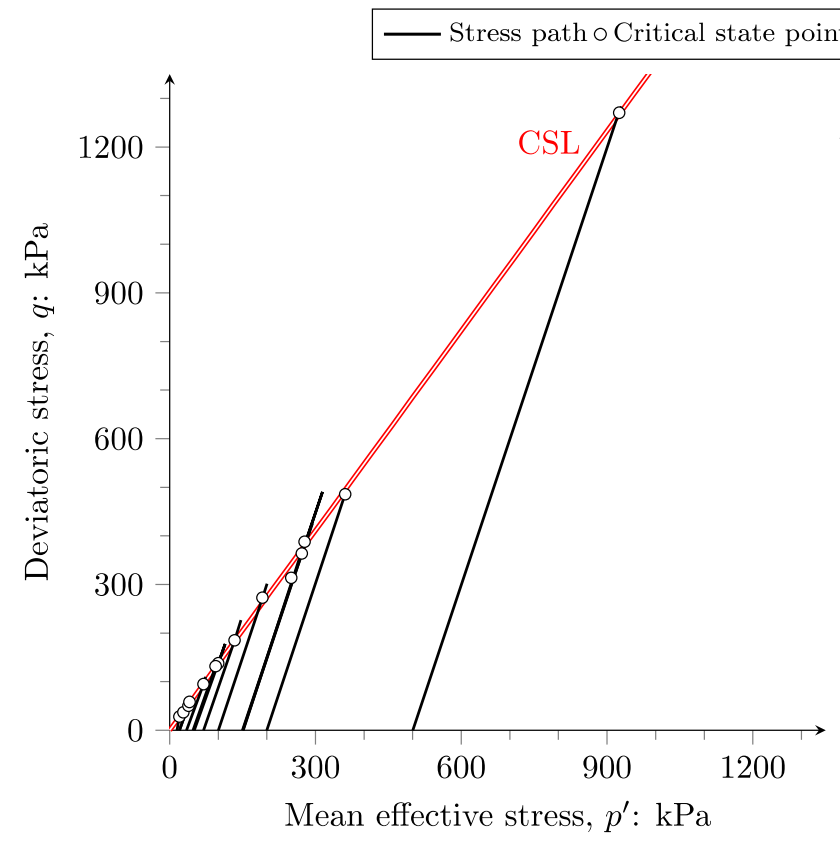

a)

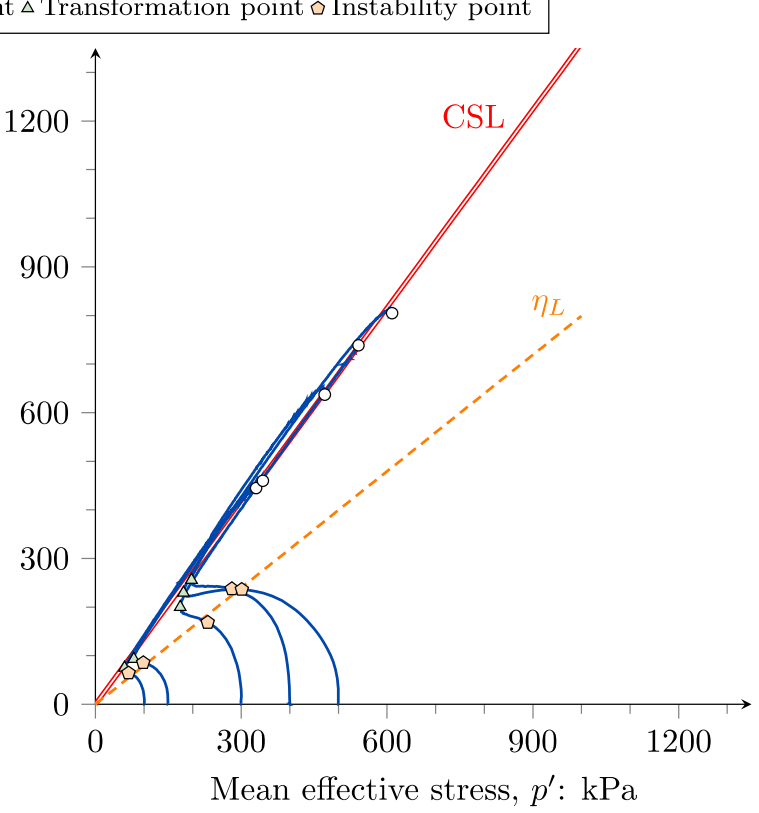

b)

Fig. 11. Stress path and CSL on $q: p^{\prime}$ invariant space: (a) drained stress behaviour; (b) undrained stress behaviour.

it was possible to identify the instability points for each test. Such instability points allowed defining an instability line $\left(\eta_{L}\right)$ with a slope of about 0.80 .

Fig. 12 shows the best-fit CSL for TP-Lisbon sand in $e$ : $\log p^{\prime}$ space. Solid diamond symbols represent the starting of drained shearing, while solid square symbols represent the starting of undrained tests. Open circles indicate the end of the triaxial tests - critical state condition- and were used to define the CSL. From Fig. 12, it can be observed that CSL is curved at low stresses, being relatively flat for $p^{\prime}<30 \mathrm{kPa}$, but subsequently it converges to a unique

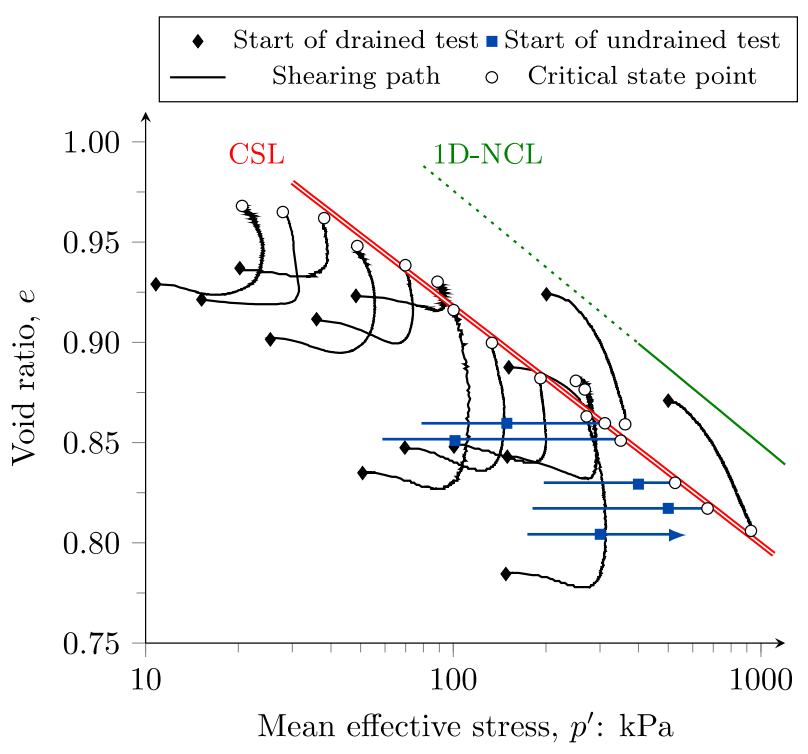

Fig. 12. Interpreted CSL with the inferred 1D-NCL and possible LCL for TP-Lisbon sand on $e: \log p^{\prime}$ invariant space. linear gradient. This effect is typical in sandy soils due to the granular packing effect -represented by $e_{\max }$ valueand flow instability at low-stress levels and high void ratio of this type of geomaterials (Carrera et al., 2011; Li et al., 2018; Murthy et al., 2007; Verdugo \& Ishihara, 1996). In this study, only the straight-linear part of the CSL will be considered to describe the behaviour of TP-Lisbon sand, although the experimental evidence showed that the CSL is curvilinear for this particular sandy soil. Such an assumption was implemented because the stress and relative density states of the curve part of CSL of TP-Lisbon sand are unlikely in practical engineering applications. The equation adopted to define the CSL in the straightlinear part is:

$\mathrm{e}_{c s}=\Gamma-\lambda \ln \left(p^{\prime}\right)$

where $e_{c s}$ is the critical state void ratio, $\Gamma$ is the void ratio defined at $p^{\prime}=1 \mathrm{kPa}$ and $\lambda$ is the slope of the CSL in the $e$ : $\log p^{\prime}$ space. Tests results allowed defining a unique CSL with a higher correlation coefficient $\left(\mathrm{R}^{2}>0.97\right)$ for TPLisbon sand with $\Gamma=1.155$ and $\lambda=0.052$. The linear approach of the Eq. (1) provides the best-fit to describe the behaviour of TP-Lisbon sand for $p^{\prime}$ from $40 \mathrm{kPa}$ to $1000 \mathrm{kPa}$ and $e$ from 0.7821 to 0.9616 . These ranges well represent the possible stress-state conditions that this sandy soil may experience in the field.

In Fig. 12, the drained state paths have a hooked shape since the void ratio change during shearing. The orientation of the hooked shape varies according to the position of the initial void ratio with respect to the CSL (i.e. above or below). Test-paths with similar shapes were observed for drained tests with both contractive and dilating behaviour. 
On the other hand, Fig. 12 showed that the undrained state paths are horizontal lines, displaying minimum values of $p^{\prime}$ different to their corresponding $p^{\prime}{ }_{0}$. This effect is due to the positive change of pore pressure caused by their initial contractive behaviour.

A comparison of the CSL for TP-Lisbon sand with other quartz sands is shown in Fig. 13. The parameters of the best-fit CSL for TP-Lisbon sand are comparable to other natural sands reported by Cho et al. (2006). By contrasting against sands with similar intrinsic properties (e.g. $D_{50}, C u, e_{\max }$ and $\left.e_{\min }\right)$, TP-Lisbon CSL sand has a similar $\lambda$ gradient and higher $\Gamma$ value, indicating that the CSL is parallel and lies in a different position concerning the reference sands. In sands with roundness values lower than 0.45 (such as Ticino sand, Blasting sand and TP-Lisbon sand), $\Gamma$ values higher than $e_{\max }$ values were observed. According to Cho et al. (2006), Yang \& Luo (2015), Altuhafi et al. (2016), Sarkar et al. (2019) and Lashkari et al. (2020), a decreasing in particle roundness and regularity lead to an increase in the $\Gamma$ parameter, meaning the CSL is located above when the sand is composed of angular particles. Therefore, the relatively high position of the TP-Lisbon CSL is attributed to the subangular shape of its particles, as also found by Ramos et al. (2019).

\section{Stress-dilatancy relation of TP-Lisbon sand}

Stress-dilatancy denotes the volumetric changes in sands as a result of mobilised shear strains and applied stresses. Stress-dilatancy is a concept regarding plastic strain rates since shear stress does not generate elastic volume change. The soil dilatation is estimated by computing the ratio between the volumetric strain increment and deviatoric strain increment $\left(d=\delta \varepsilon_{v} / \delta \varepsilon_{s}\right)$, providing relevant elements to assess the behaviour of granular materials. For undrained conditions, the soil dilatation is estimated by the rate of change of the deviatoric strain increment $(\delta \Delta$ $u / \delta \varepsilon_{a}$ ), where $\delta \varepsilon_{a}=\delta \varepsilon_{s}$ since there is no volume change in undrained testing. Soil dilatation only considers the plastic volumetric strains because the elastic volumetric strains are very small and, thus, negligible (Been \& Jefferies, 2004). Fig. 14 presents the development of the stress ratio $\left(\eta=q / p^{\prime}\right)$ with the axial strain, the evolution of stressdilatancy (for drained tests) and the normalised pore pressure in terms of volumetric strains (for undrained tests).

From Fig. 14.a, it can be observed a convergence of the stress ratio to a single $\eta$ value of about 1.37, at large axial stains, for both drained and undrained tests. This value agrees with the $M$ value identified in Fig. 11. Such a convergence occurs when $\delta \varepsilon_{v} / \delta \varepsilon_{s}$ and $\delta \Delta u / \delta \varepsilon_{a}$ are zero, confirming that all tests reached the critical state condition in all tests, except TxU17-300. On the other hand, negative dilation rates with peak strengths higher than the final value achieved at the end of the tests are evidenced in Fig. 14. $\mathrm{b}$, indicating the effects of stress-dilatancy on specimens with states below the critical state line. Fig. 14.c plots the stress-ratio results of undrained tests. This Figure shows that when the pore pressure rate $\left(\delta \Delta u / \delta \varepsilon_{a}\right)$ is zero, the soil moves upwards until the maximum shear strength value and then moves downwards to the critical state condition.

The stress-dilatancy curves of TP-Lisbon sand revealed a clear reversal once the soil reaches the peak stress ratio $\left(\eta_{\max }\right)$, following to the critical state (see Fig. 14.b). This behaviour was observed in the negative values of volumetric strains rate, indicating the maximum dilation rate $\left(d_{m}\right)$ of all tests. Experimental data show that TP-Lisbon sand is highly dilatant, mainly at lower values of confinement stress. This behaviour is typical of angular and subangular

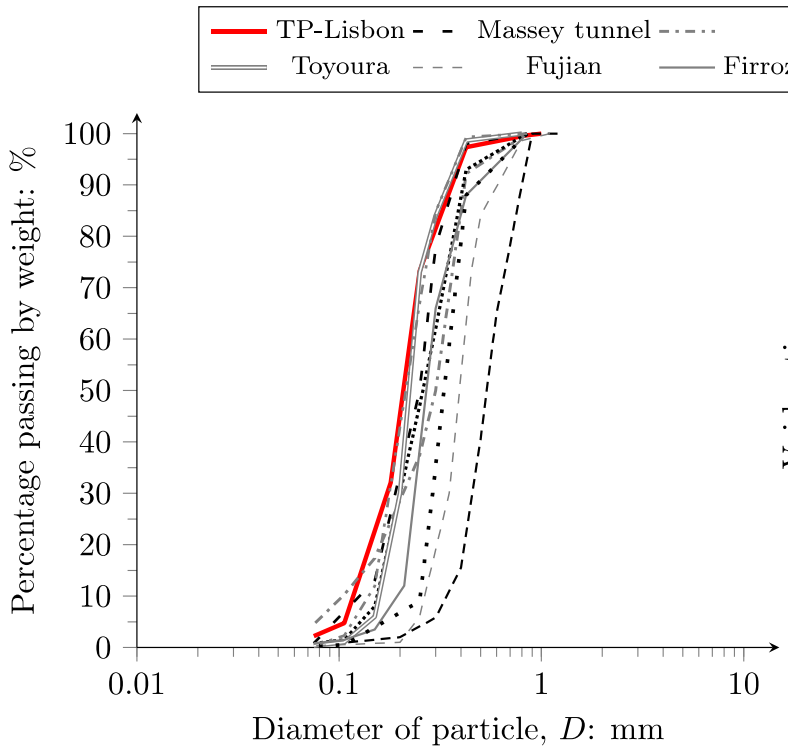

a)
Lornex - - - - Ticino …….. Freaser River rrozkuh No. 161 ... Hostun -.... Ottawa

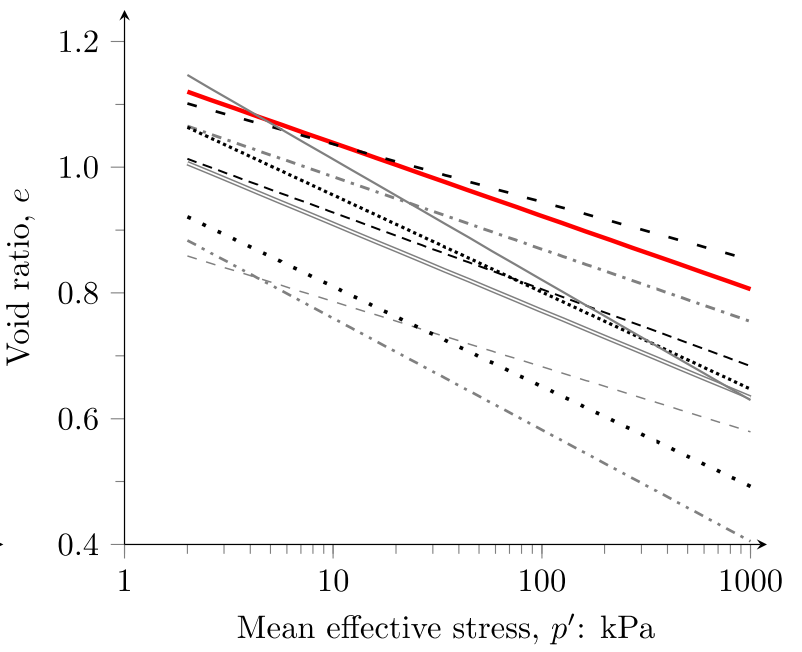

b)

Fig. 13. Comparison of TP-Lisbon against other sands with similar intrinsic properties: (a) GSD; (b) CSL. 


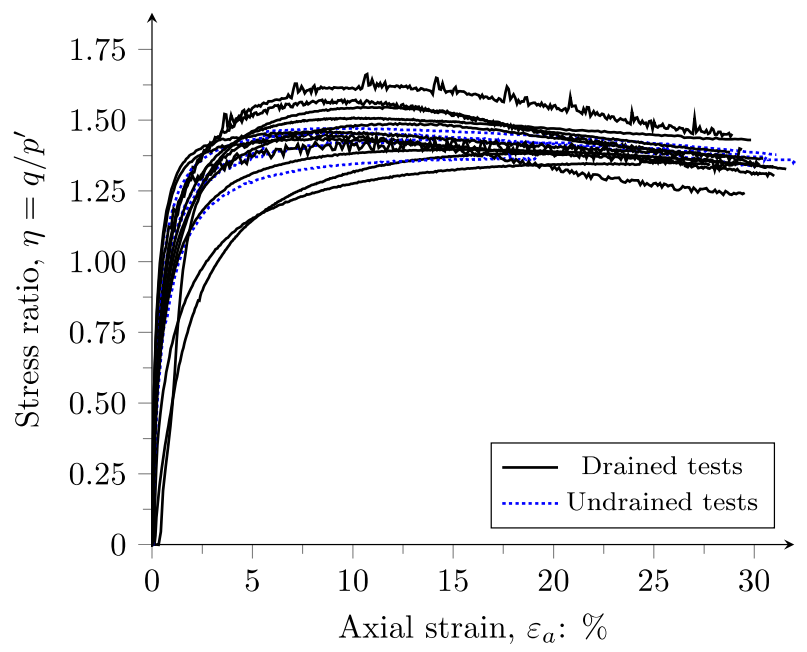

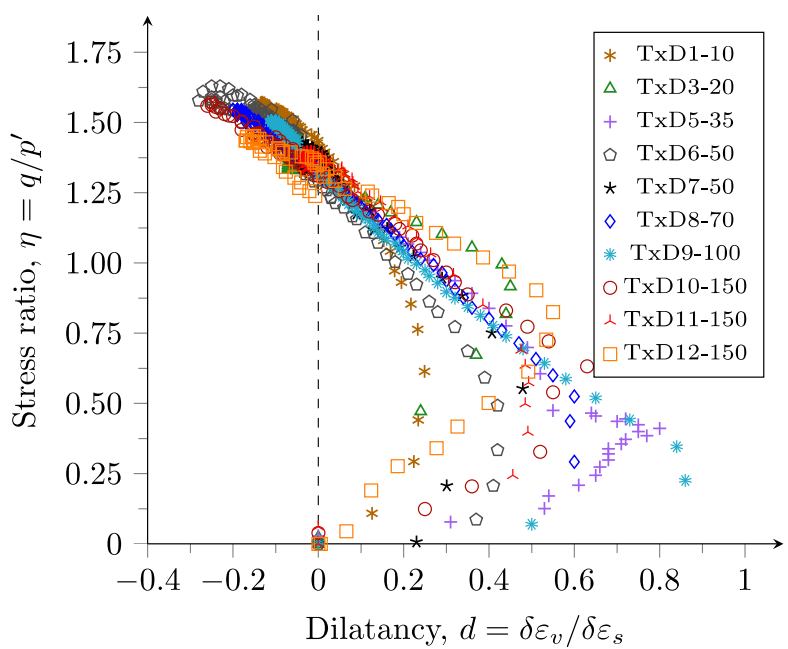

b)

a)

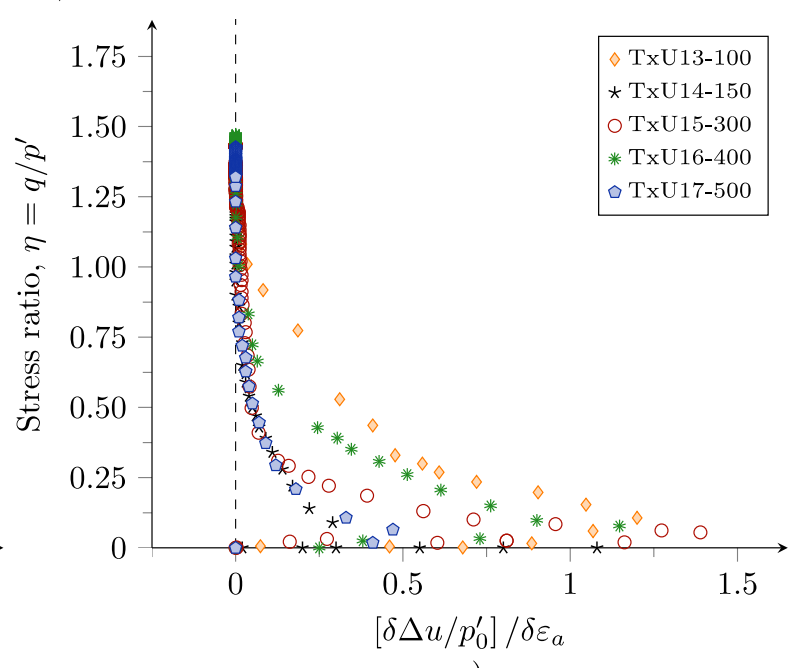

c)

Fig. 14. Stress ratio relationships: (a) stress ratio behaviour; (b) dilation rate for drained tests; (c) stress ratio plotted against the normalised pore pressure change for undrained tests.

sands (Nguyen et al., 2020) and was also observed by Been \& Jefferies (2004) for loose quartz sands.

The soil stress-dilatancy behaviour of sands can be represented by plotting the $\eta_{\max }$ of the drained tests as a function of $d_{m}$ (Nova, 1982). This relation incorporates a volumetric coupling parameter $(N)$, as indicated in Eq. (2).

$\eta_{\max }=M-(1-N) d_{m}$

Eq. (2) provides an inverse linear relationship between both variables -that is, higher values of $\eta_{\max }$ for lower values of $d_{m}$. For TP-Lisbon sand, it was found that $N=0.17$ provides the best fitting to describe the evolution of $\eta_{\max }$ in terms of $d_{m}$. Fig. 15 shows the relationship between $\eta_{\max }$ and $d_{m}$ of TP-Lisbon sand in the same triaxial test compared against the model of equation (2). Moreover, Fig. 15 indicates that the intercept at zero dilatancy is 1.37, which corresponds to the same value of $M$ inferred in Fig. 11.

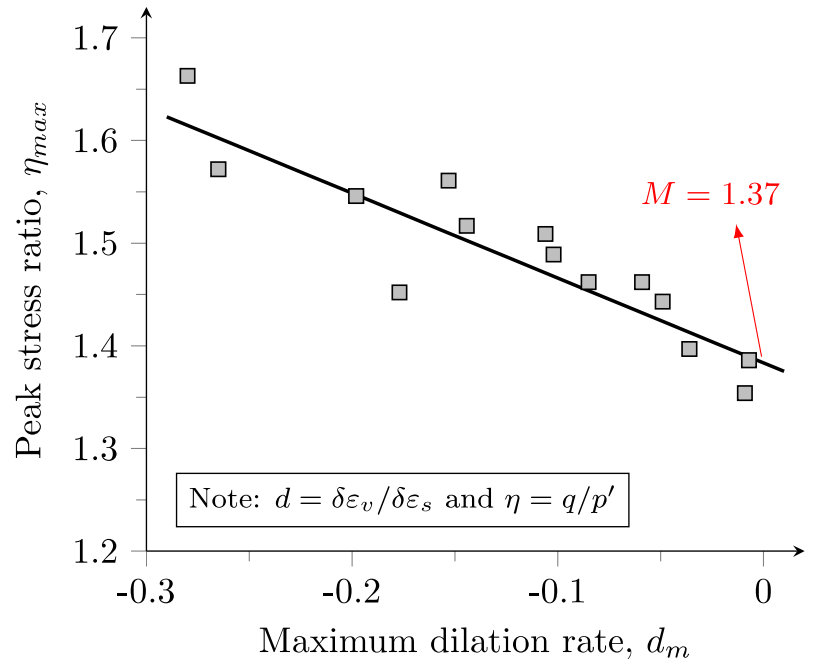

Fig. 15. Peak stress ratio and maximum stress-dilatancy of TP-Lisbon sand. 


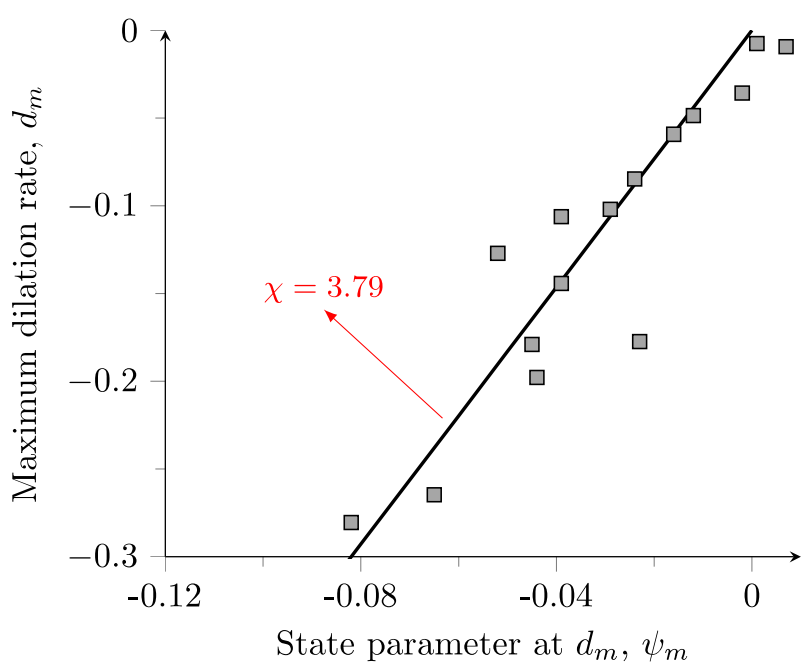

Fig. 16. Dilatancy scaling for TP-Lisbon sand.

Another way to interpret the stress-dilatancy behaviour of granular materials using the CSSM framework is the combining of $d_{m}$ with the state parameter $(\psi)$-defined as the difference or distance between the current void ratio and the void ratio on the CSL at the same stress-state (Been \& Jefferies, 1985). This novel interpretation allows estimating the rate of dilation through the dilatancy rate scaling parameter $(\chi)$, which is the line slope obtained from the relationship between $d_{m}$ values and their corresponding $\psi$ at which $d_{m}$ occurs. Jefferies \& Been (2015) claimed that $\chi$ is a material property that captures the maximum dilatation of the soil and ranges typically from 2 to 5 . However, for uniform and clean sands, this parameter ranges from 3.5 to 4.0 according to the particle shapes. Fig. 16 shows the derivation of $\chi=3.79$. This Figure indicates a good agreement to the typical values for quartz sands, usually assumed as 3.5 (Giretti et al., 2018).

\section{Stress-dependency of small-strain stiffness in TP-Lisbon sand}

Stress-dependency of small-strain stiffness of TP-Lisbon sand was investigated by means of bender element (BE) tests. These tests were conducted for dry and saturated conditions under different confining stresses. Specimens were prepared according to the procedure described in section 2 for a relative density of about $30 \%$, corresponding to the state of TP-Lisbon sand on the field (see Fig. 2). The wave propagation time $\left(t_{t}\right)$ between BE tip-to-tip distance $\left(L_{t t}\right)$ at each $p^{\prime}$ was assessed using the first arrival method, for both shear and compression waves, as specified in Section 2.3. To minimise the uncertainty and subjectivity associated with the interpretation of test results (e.g. cross-talk or near-field effect), four input signals with frequencies between 1 and $8 \mathrm{kHz}$ and $25-125 \mathrm{kHz}$ were applied to assess $V s$ and $V p$, respectively (Viana da Fonseca et al., 2009). Fig. 17 presents some typical results of BE measurements for both $V s$ and $V p$ at different test conditions.

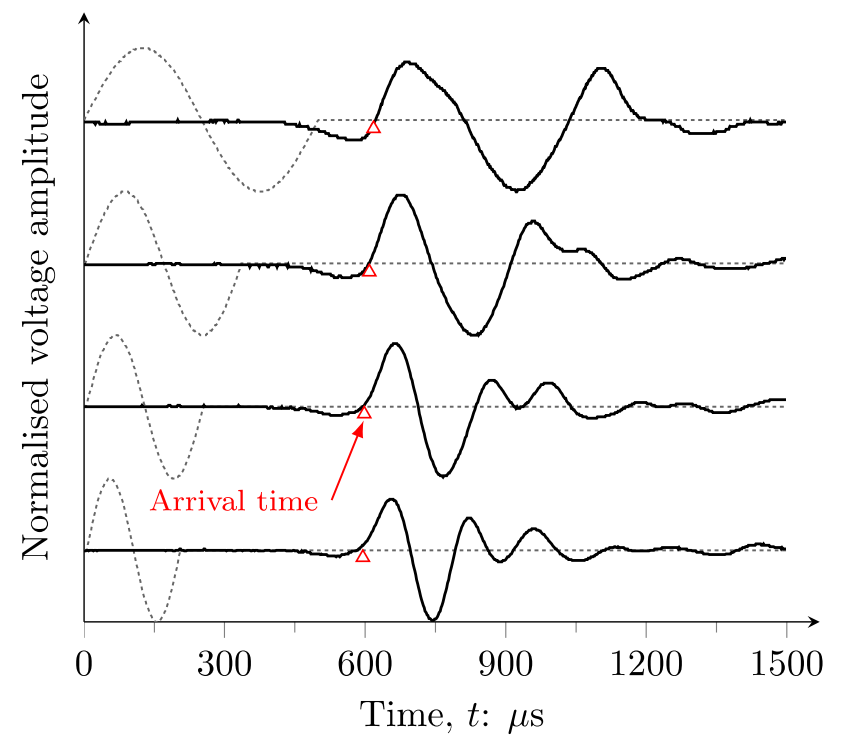

a)

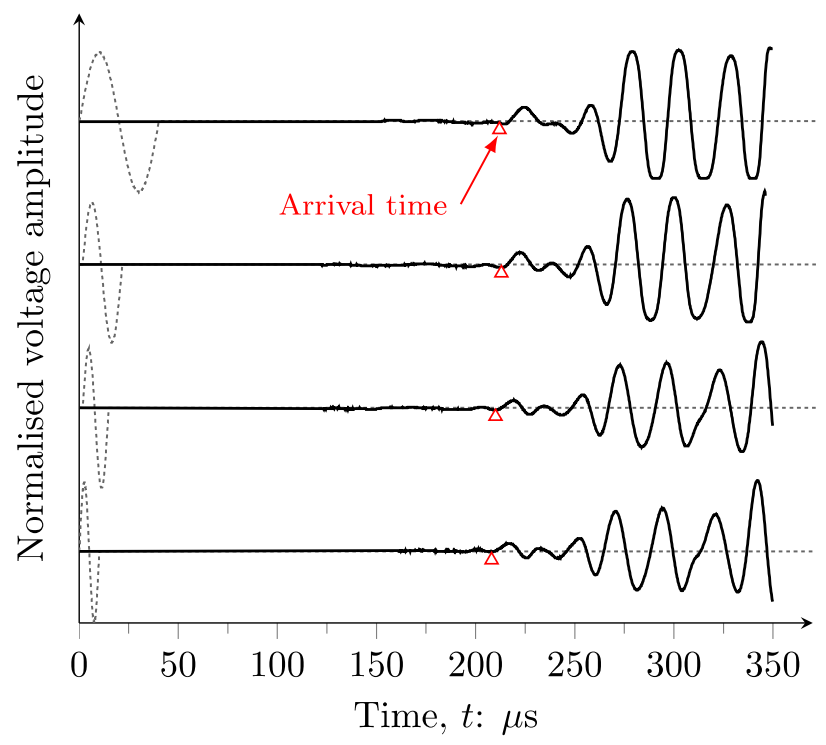

b)

Fig. 17. Typical time-domain signals of BE: (a) $V s$ signal at $150 \mathrm{kPa}$ confining stress in a saturated sample; (b) $V p$ signal at $200 \mathrm{kPa}$ confining stress in a dry sample.

BE tests have been analysed to derive the best fit of wave velocities ( $V s$ and $V p$ ) stress-dependency using:

$V_{s}=\alpha\left(p^{\prime}\right)^{\beta}$

$V p=\theta\left(p^{\prime}\right)^{\beta}$

where $\alpha$ and $\theta$ are the values of $V s$ and $V p$ at $1 \mathrm{kPa}$, respectively, and $\beta$ is the exponent of the stress-state dependency law of wave propagation velocities. The $V p$ values obtained for saturated conditions ranged from $1495 \mathrm{~m} / \mathrm{s}$ to $1513 \mathrm{~m} / \mathrm{s}$, corresponding to typical results for fluid-saturated granular media (Biot, 1956). Therefore, the stress-dependency model of $V p$ for saturated conditions was not estimated. The $V s$ results obtained from $\mathrm{BE}$ tests were contrasted 
against $V S$ values obtained from resonant-column (RC) tests reported by Molina-Gómez et al. (2020). Such an RC apparatus corresponds to a Stokoe type -bottomfixed and top free configuration- equipped with an automatic system able to control all the testing phases. Besides, the RC apparatus has an internal function generator with a digital interface, which can generate different types of voltage signals to the coils attached to the cell body and then generating a proportional torque. Fig. 18 shows the stress-dependent seismic wave velocities of $V s$ and $V p$ for TP-Lisbon sand. Table 6 presents the values of the stressdependency fitting parameters.

Results of stress-dependency seismic wave velocities for TP-Lisbon sand showed very close $\beta$ values for all tests, revealing parallel evolutions of the wave velocities as a function of the stress-state. It should be noted that $V s$ and $V p$ values obtained from the measurements in dry conditions have the same evolution but with higher values in $V p$. Furthermore, from the BE-d results, the Poisson ratio (v) was computed for each mean stress, finding a mean value of 0.35 with a coefficient of variation equal to $5 \%$ for loose conditions. On the other hand, similitudes between results for the same testing method were observed, which shows that $\mathrm{BE}$ and $\mathrm{RC}$ measurements allow estimating the small-strain stiffness of sands (Camacho-Tauta et al., 2015).

It is well- known that $V S$ is affected by void ratio and confining stress. Hence, the small-strain stiffness of soils should be represented by a normalised model. Eq. (5) intro-

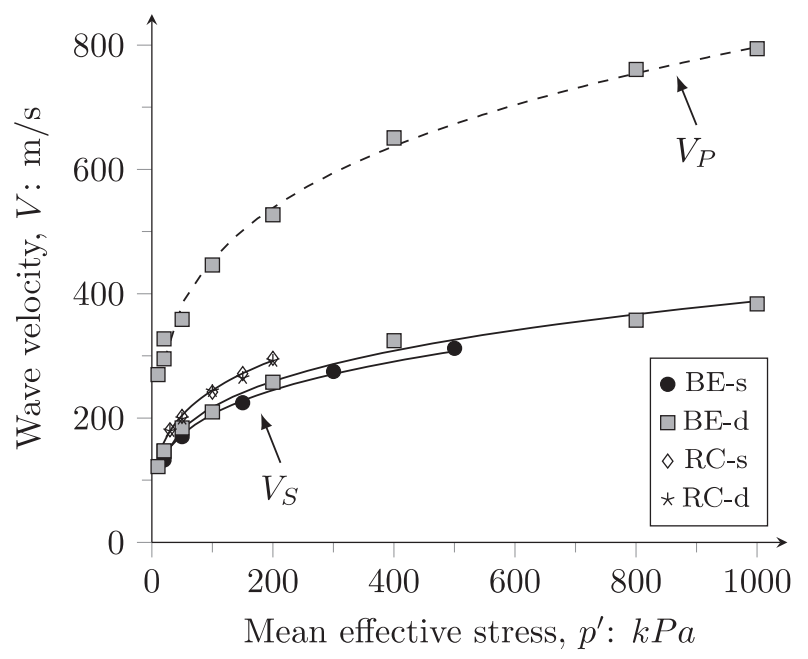

Fig. 18. Stress-dependency of seismic wave velocities for TP-Lisbon sand.

Table 6

Fitting parameters of stress-dependency of seismic wave velocities.

\begin{tabular}{llcl}
\hline Test name & Seismic wave type & $\alpha$ or $\theta: \mathrm{m} / \mathrm{s}$ & $\beta:$ dimensionless \\
\hline BE-s & $V s$ & 68.75 & 0.2484 \\
BE-d & $V s$ & 65.68 & 0.2505 \\
BE-d & $V p$ & 148.40 & 0.2433 \\
RC-s & $V s$ & 74.31 & 0.2588 \\
RC-d & $V s$ & 73.74 & 0.2576 \\
\hline
\end{tabular}

duces a generalised stress-state model for describing the small-strain stiffness of TP-Lisbon sand. This model is based on the stress-dependency of shear wave velocity $(V s)$, but expressed in terms of maximum shear modulus $\left(G_{0}\right)$, as follows:

$G_{0}=V s^{2} D=F(e) C\left(p^{\prime} / p_{a}\right)^{n}$

where $D$ is mass density, $p^{\prime}$ is mean effective stress, $P a$ is the atmospheric pressure (used as reference stress), $\mathrm{F}(e)$ is a void ratio function, $C$ and $n$ are two material constants. Based on experimental evidence, Molina-Gómez et al. (2020) defined $\mathrm{F}(e)=e^{-1.79}, \quad C=65.11 \mathrm{MPa}$ and $n=0.48$ for TP-Lisbon sand. However, these authors carried out tests for the full saturation conditions. In this study, a comparison between the normalised shear modulus for dry and saturated conditions was conducted to validate the stress-state model describing the stressdependency seismic shear wave velocity in these extreme conditions. Fig. 19 presents a comparison between the normalised shear modulus computed from experimental data reported in Fig. 18 against the stress-state model proposed by Molina-Gómez et al. (2020). The computation of Eq. (5) required the previous estimation of $D$. This estimation considered the degree of saturation of the soil specimens -that is, $D$ for dry and saturated conditions, respectively.

A contrast between results from dry and saturated specimens revealed that there are no substantial differences in the normalised small-strain stiffness of TP-Lisbon sand for these conditions. On the other hand, a good agreement between $\mathrm{BE}$ and $\mathrm{RC}$ results with the normalised model was found. The use of the stress-state model is conceptually more consistent for describing the small-strain stiffness of granular materials due to the double normalisation, which eliminates the effects of void ratio and confinement stress. Besides, the application of such a model allows comparing the small-strain stiffness of TP-Lisbon sand against other sandy soils at different relative densities and stress-states.

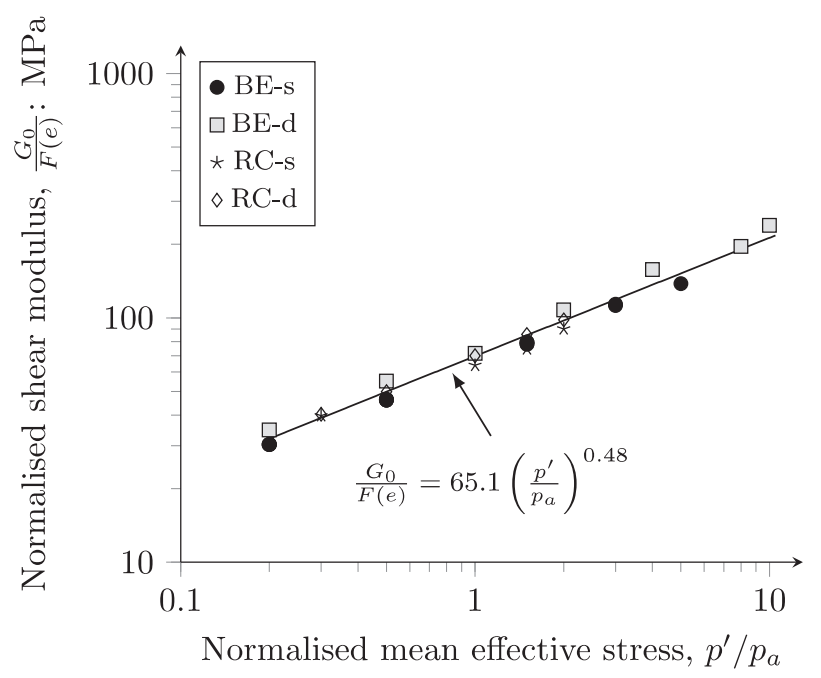

Fig. 19. Normalised shear modulus results. 


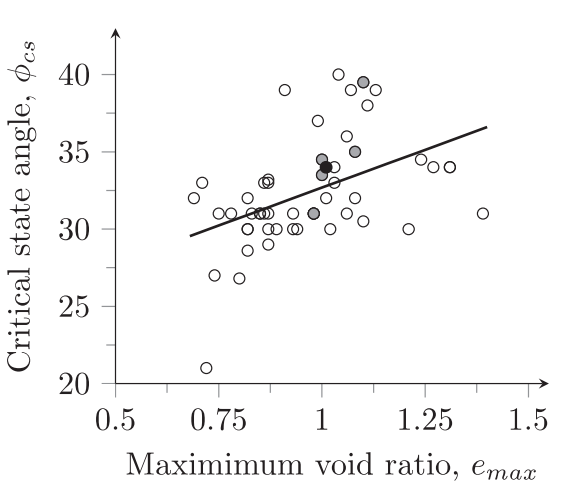

a)

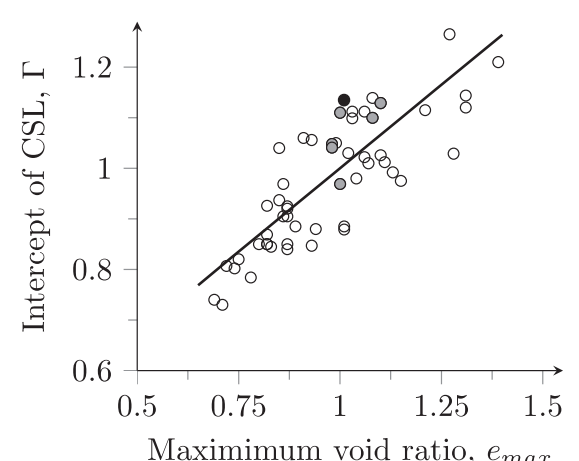

d)

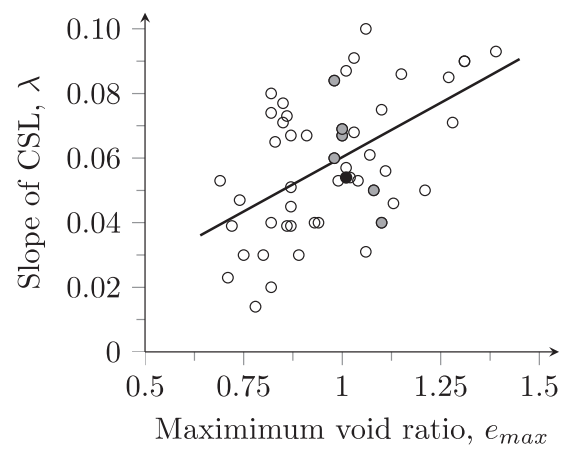

g)

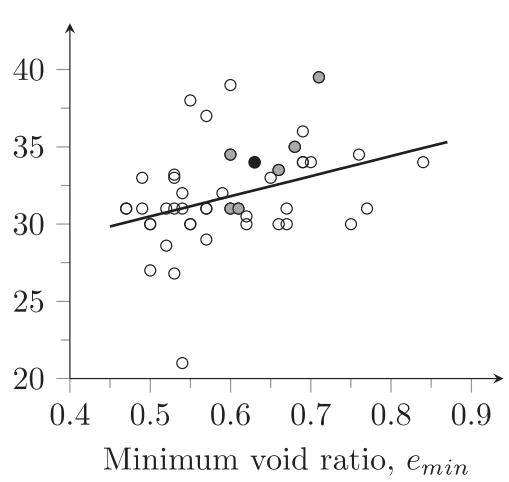

b)

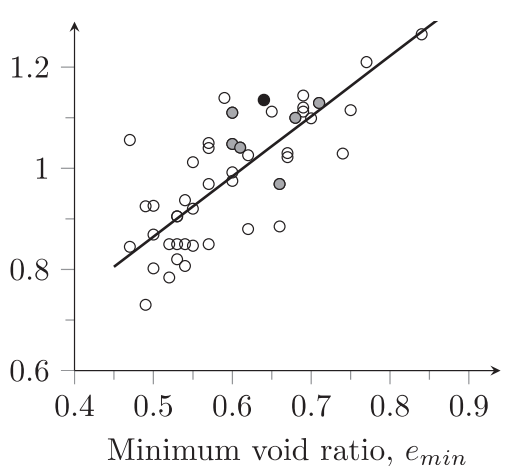

e)

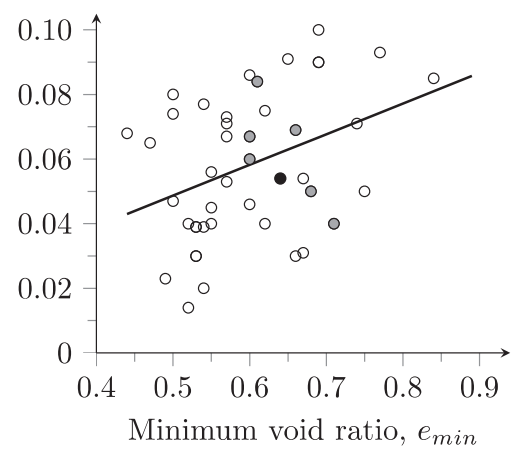

h)

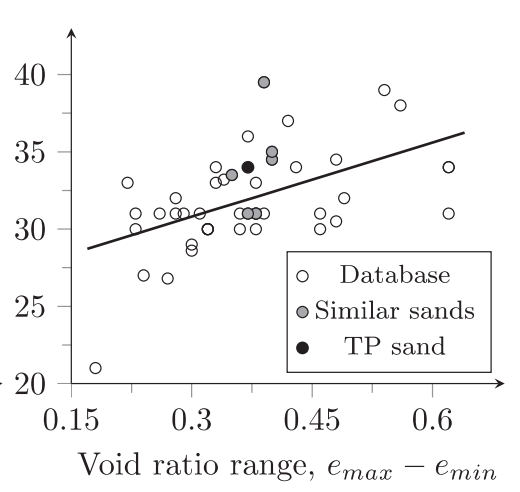

c)

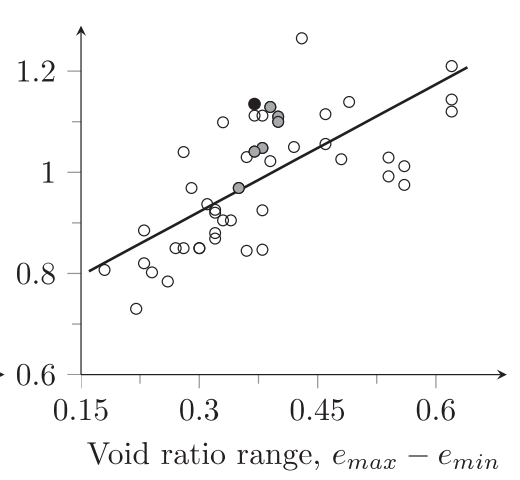

f)

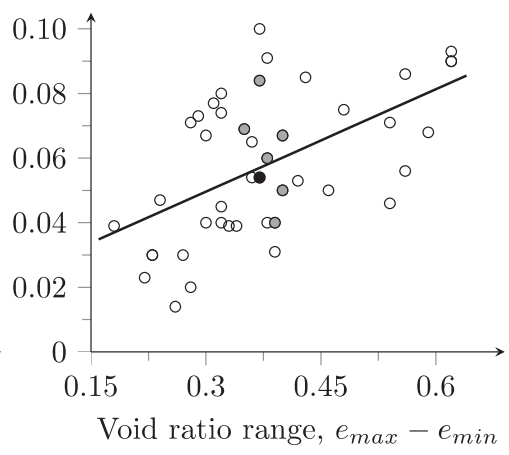

i)

Fig. 20. Relationships between granular packing with critical state parameters: (a) $\phi_{\mathrm{cs}}$ vs. $e_{\max } ;$ (b) $\phi_{\mathrm{cs}}$ vs. $e_{\min } ;$ (c) $\phi_{\mathrm{cs}}$ vs. $e_{\max }-e_{\min } ;$ (d) $\Gamma$ vs. $e_{\max } ;$ (e) $\Gamma$ vs. $e_{\min }$; (f) $\Gamma$ vs. $e_{\max }-e_{\min } ;$ (g) $\lambda$ vs. $e_{\max } ;$ (h) $\lambda$ vs. $e_{\min } ;$ (i) $\lambda$ vs. $e_{\max }-e_{\min }$.

\section{Effects of particle shape and granular packing on the behaviour of TP-Lisbon sand}

Previous studies showed that particle shape and granular packing characteristics affect the critical state and small-strain stiffness parameters of sands and non-plastic soils (Altuhafi et al., 2016; Cho et al., 2006; Cubrinovski \& Ishihara, 2002; Li et al., 2018; Torres-Cruz \& Santamarina, 2019). This section discusses the effect of particle shape and granular packing on critical state parameters based on the experimental results presented in this paper and an existing database from Cho et al. (2006), Yang \& Luo (2015), Altuhafi et al. (2016) Sarkar et al. (2019) and Lashkari et al. (2020). The comparisons highlight the sands with similar intrinsic properties than TP-Lisbon sand. The objective of these comparisons is to assess the behaviour consistency of TP-Lisbon sand, explained in terms of particle shape and granular packing.

Fig. 20 presents the relationships between granular packing with critical state parameters, indicating a positive linear increment of all critical state parameters when increasing the values of packing parameters. Results indicated that the relationships with best agreement are $\phi_{\mathrm{cs}}$ and $\Gamma$ with the three packing parameters. Besides, Fig. 20 shows that the spread in $e_{\max }$ is lower than that in $e_{\min }$ and void ratio range.

Fig. 21 presents the relationships between particle shape properties with critical state parameters. From Fig. 21, it was observed that the sands composed of angular particles have higher values of critical state parameters (i.e. $\phi_{\mathrm{cs}}, \Gamma$ 


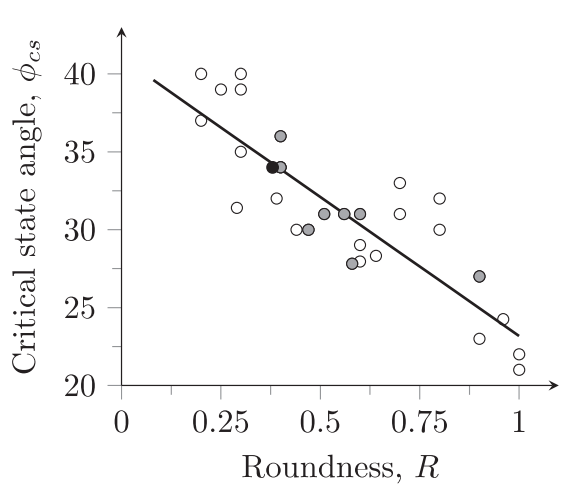

a)

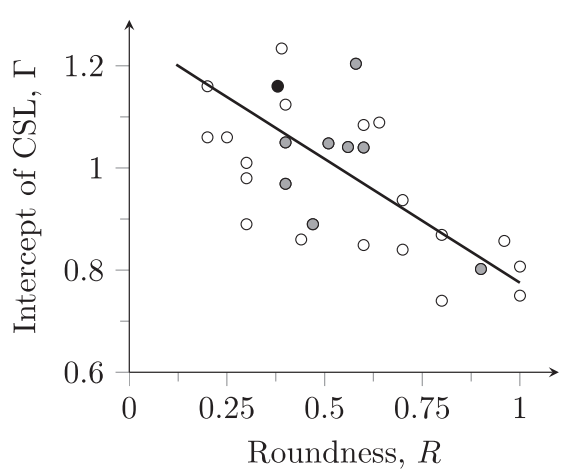

d)

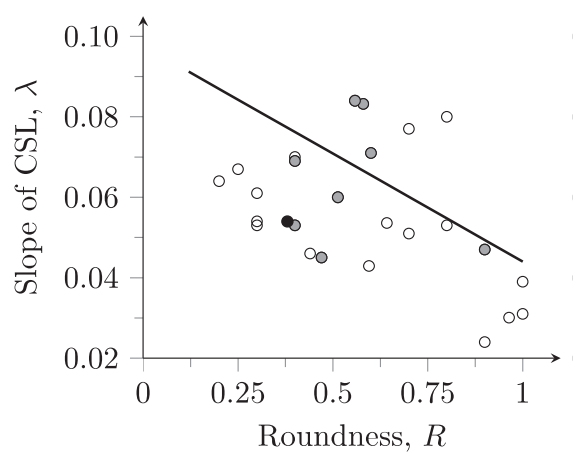

g)

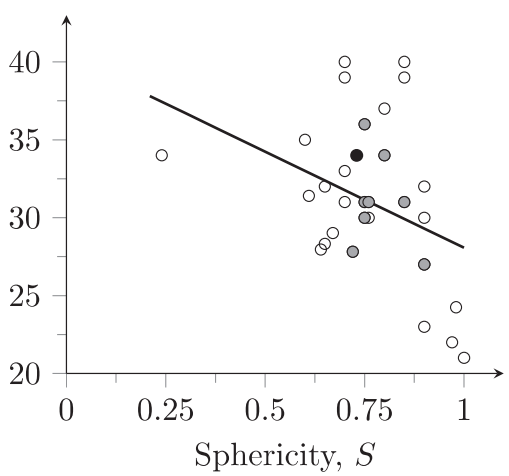

b)

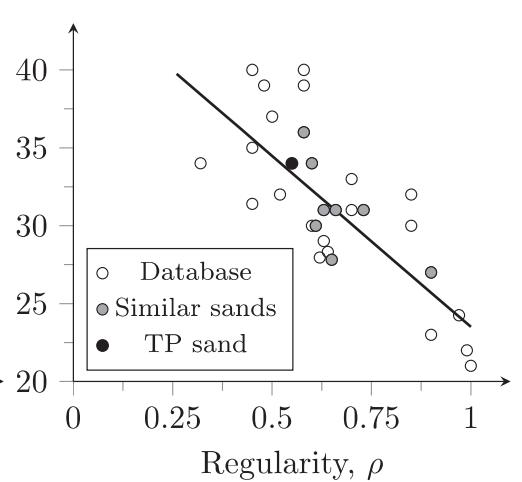

c)

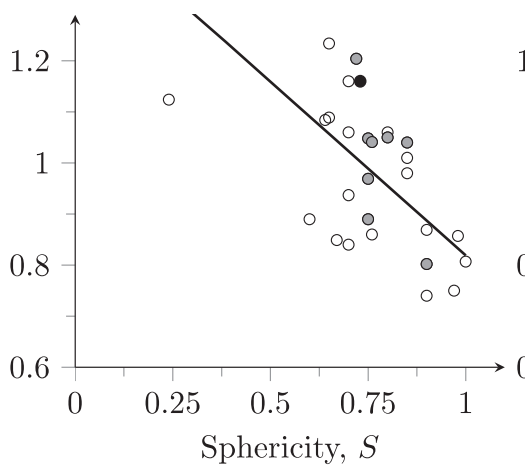

e)

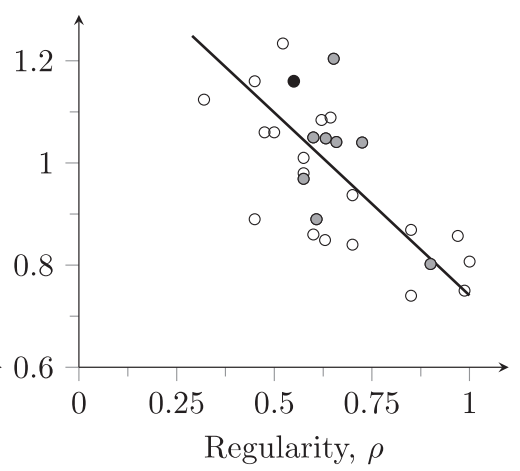

f)

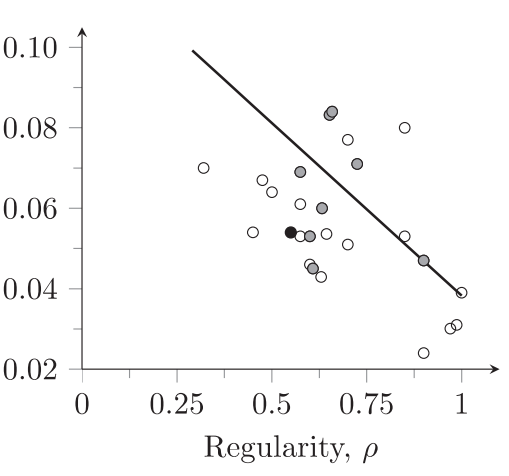

i)

Fig. 21. Relationships between particle shape properties with critical state parameters: (a) $\phi_{\mathrm{cs}}$ vs. $R$; (b) $\phi_{\mathrm{cs}}$ vs. $S$; (c) $\phi_{\mathrm{cs}}$ vs. $\rho$; (d) $\Gamma$ vs. $R$; (e) $\Gamma$ vs. $S$; (f) $\Gamma$ vs. $\rho$; (g) $\lambda$ vs. $R$; (h) $\lambda$ vs. $S$; (i) $\lambda$ vs. $\rho$.

and $\lambda$ ) than the sand with spherical particles. $R$ and $\rho$ presented the best fitting with $\phi_{\mathrm{cs}}$ and $\Gamma$. Note that there is no clear clustering of $\lambda$ as a function of particle shape properties, as also observed by Torres-Cruz \& Santamarina (2019). Therefore, the granular packing and shape of particles have a strong influence only in the $\phi_{\mathrm{cs}}$ and $\Gamma$ parameters of sandy soils.

For the specific case of TP-Lisbon sand, $e_{\max }, R$ and $\rho$ are the best parameters for describing the relatively high position of the CSL since particle shape and granular packing affect the intercept of the CSL in the $e: \log p^{\prime}$ space, but not the slope of the CSL. This effect induces and controls the predominant dilative behaviour of this sandy soil in the low-pressure range. In addition, it was observed that the particle shape of TP-Lisbon sand controls the shearing resistance at large strains and its critical state parameters.

Fig. 22 shows a comparison between parameters describing the normalised small-strain stiffness and particle shape of TP-Lisbon sand (referred in Fig. 18). This comparison includes values reported by Liu \& Yang (2018). A good correlation between parameter $C$ and exponent $n$ with sphericity, circularity and convexity was observed. These correlations revealed that an increment of shape parameter causes a decreasing of parameter $C$, while an increment of shape parameter causes a decreasing of exponent $n$. Hence, experimental results validate the effects of particle shape on the behaviour of TP-Lisbon sand. 


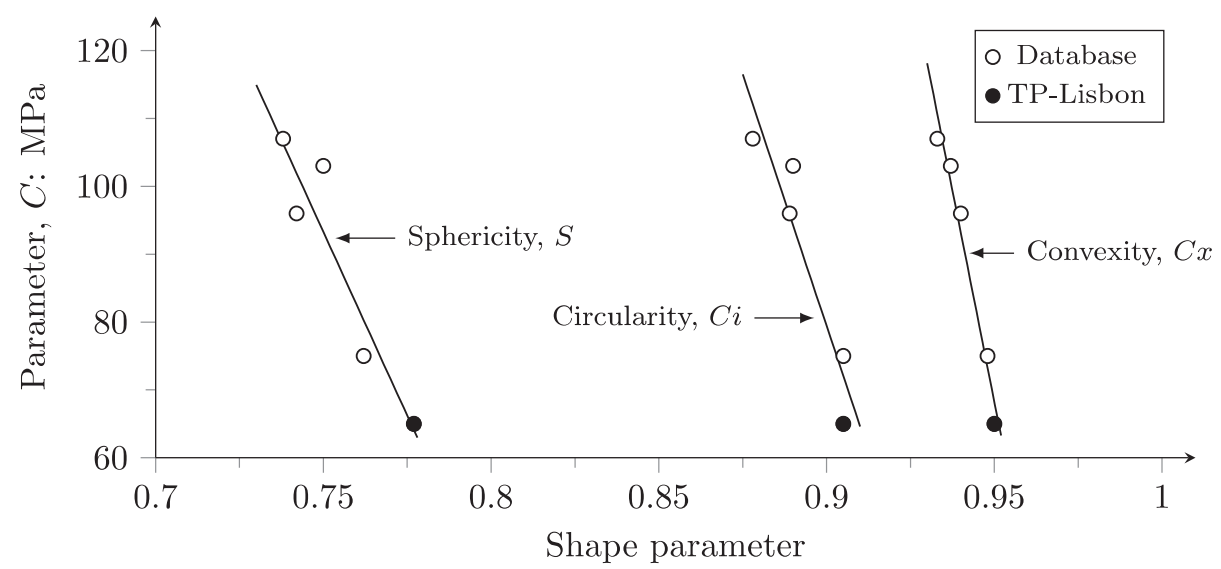

a)

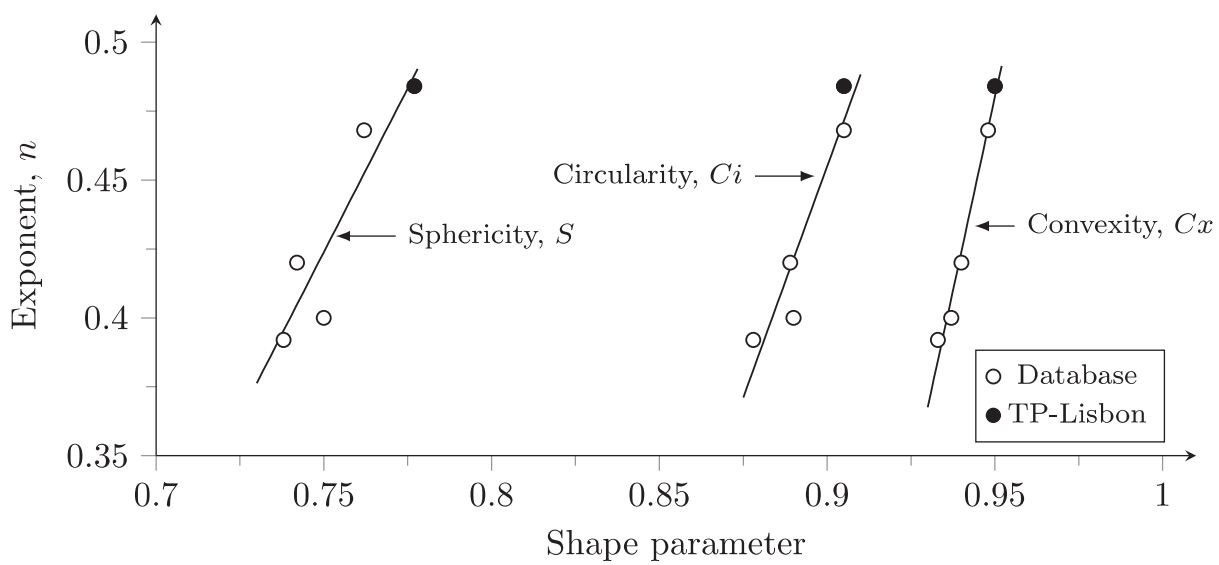

b)

Fig. 22. Relationships between particle shape properties with normalised small-strain stiffness parameters: (a) Parameter $C$; (b) Exponent $n$.

\section{Concluding remarks}

This paper presented the results of a detailed characterisation of the key geomechanical properties of TP-Lisbon sand, a historically liquefiable soil from the greater Lisbon area. This sand is a natural quartz fine and poorly graded sand with a predominant subangular shape. The behaviour and geomechanical properties of TP-Lisbon sand are comparable to other natural sands that have similar intrinsic properties (e.g. $D_{50}, C u, e_{\max }$ and $e_{\min }$ ) and morphological parameters. The intention of the authors with this paper is to provide quality data from well-controlled and accurate test procedures to provide reliable results on the behaviour of this natural sand. This intention can contribute to ongoing research, calibration/validation of constitutive models or additional data for geotechnical design in such a sensitive zone in the heart of the historical centre of Lisbon, but also to be adopted in similar sandy soils.

The well-controlled and accurate test procedures (e.g. lubricated end platens, top cap-loading ram connection and end-of-test soil freezing) and experimental results led to the following conclusions:
- TP-Lisbon sand presented the highest critical state locus position (higher value of $\Gamma$ ) regarding the data of the other similar sands.

- Due to a higher value of $\Gamma$, the behaviour of TP-Lisbon sand is predominant dilative behaviour during monotonic/static loading.

- The CSL position of TP-Lisbon sand was explained by particle shape and granular packing characteristics of this sandy soil, namely $e_{\max }, R$ and $\rho$.

- TP-Lisbon achieves its peak deviatoric stress and, then its maximum shear strength, in about $10-15 \%$ axial strain, while its volumetric strain stabilisation after $25 \%$ axial strain.

- It was observed that, for undrained conditions, the phase transformation of TP-Lisbon sand occurred at $1-2 \%$ axial strain and the deviatoric stress stabilisation in about $20-25 \%$ axial strain.

- TP-Lisbon sand did not present particle crushing when applied $\sigma^{\prime}$ below $1600 \mathrm{kPa}$. However, above this stress range, the slope of oedometer compression curves increased, indicating a possible manifestation of such a phenomenon. 
- The one-dimensional compressibility and small-strain shear modulus of TP-Lisbon sand are similar for dry and saturated conditions.

- There is a strong correlation between normalised shear modulus of TP-Lisbon sand with its particle shape parameters, confirming the influence of particle shape on the geomechanical behaviour of TP-Lisbon sand.

\section{Acknowledgements}

The authors would like to acknowledge to the Portuguese Foundation for Science and Technology (FCT) for the support of the PTDC/ECM/GEO/1780/2014 project 'Liquefaction Assessment Protocols to Protect Critical Infrastructures against Earthquake Damage: LIQ2PROEARTH'. The first author also acknowledges the support of FCT through grant SFRH/BD/146265/2019. This work was also financially supported by UIDB/04708/2020 and UIDP/04708/2020 of CONSTRUCT - Institute of R\&D in Structures and Construction, Portugal funded by the national funds through the FCT/MCTES (PIDDAC). Acknowledgements are especially due to Dr Cristina Raminhos from 'Metropolitano de Lisboa' for providing the samples of TP-Lisbon sand, as well as to Dr Béatrice Baudet and Eng Catarina Ramos for providing the test results of the morphology of soil particles carried out using the Morphologi G3-ID equipment at UCL. Thankfulness is due to Dr Cristiana Ferreira for her support in the interpretation of $\mathrm{BE}$ tests.

\section{References}

Altuhafi, F.N., Coop, M.R., Georgiannou, V.N., 2016. Effect of particle shape on the mechanical behavior of natural sands. J. Geotech. Geoenviron. Eng. 142 (12), 04016071. https://doi.org/10.1061/(ASCE) GT.1943-5606.0001569.

ASTM International. D422 - Standard Test Method for Particle-Size Analysis of Soils (2007).

ASTM International. D 4253 - Test Methods for Maximum Index Density and Unit Weight of Soils Using a Vibratory Table (2016).

ASTM International. D4254 - Standard Test Methods for Minimum Index Density and Unit Weight of Soils and Calculation of Relative Density (2016).

ASTM International. ASTM D6913/D6913M - 17 Standard Test Methods for Particle-Size Distribution (Gradation) of Soils Using Sieve Analysis (2017).

Been, K., Jefferies, M., 1985. A state parameter for sands. Géotechnique 35 (2), 99-112. https://doi.org/10.1680/geot.1985.35.2.99.

Been, K., Jefferies, M., 2004. Stress-dilatancy in very loose sand. Can. Geotech. J. 41 (5), 972-989. https://doi.org/10.1139/T04-038.

Been, K., Jefferies, M., Hachey, J., 1991. The critical state of sands. Géotechnique $41 \quad$ (3), 365-381. https://doi.org/ 10.1680/geot.1991.41.3.365.

Biot, M.A., 1956. Theory of propagation of elastic waves in a fluidsaturated porous solid I. low-frequency range. J. Acoust. Soc. Am. 28, $168-178$.

Boulanger, R.W., Idriss, I.M., 2014. CPT and SPT based liquefaction triggering procedures. Davis. Retrieved from http://nees.ucdavis.edu/ publications/Boulanger_Idriss_CPT_and_SPT_Liq_triggering_CGM14-01_2014.pdf
Camacho-Tauta, J., Cascante, G., Viana da Fonseca, A., Santos, J.A., 2015. Time and frequency domain evaluation of bender element systems. Géotechnique 65 (7), 548-562. https://doi.org/ 10.1680/geot.13.P.206.

Carrera, A., Coop, M., Lancellota, R., 2011. Influence of grading on the mechanical behaviour of Stava tailings. Géotechnique 61 (11), 935 946. https://doi.org/10.1680/geot.9.P.009.

CEN. Eurocode 8: Design of structures for earthquake resistance, Pub. L. No. Eurocode 8, European Committee for Standardization 229 (2010).

Cho, G.-C., Dodds, J., Santamarina, J.C., 2006. Particle shape effects on packing density, stiffness, and strength: natural and crushed sands. J. Geotech. Geoenviron. Eng. 132 (5), 591-602. https://doi.org/10.1061/ (ASCE)1090-0241(2006)132:5(591).

Couto, R., Bento, R., Gomes, R.C., 2020. Seismic performance and fragility curves of historical residential buildings in Lisbon downtown affected by settlements. Bull. Earthq. Eng. 18 (11), 5281-5307. https:// doi.org/10.1007/s10518-020-00906-z.

Cubrinovski, M., Ishihara, K., 2002. Maximum and minimum void ratio characteristics of sands. Soils Found. 42 (6), 65-78. https://doi.org/ 10.3208/sandf.42.6_65.

Ferreira, C., Viana da Fonseca, A., Ramos, C., Saldanha, A.S., Amoroso, S., Rodrigues, C., 2020. Comparative analysis of liquefaction susceptibility assessment methods based on the investigation on a pilot site in the greater Lisbon area. Bull. Earthq. Eng. 18, 109-138. https://doi. org/10.1007/s10518-019-00721-1.

Gajo, A., Wood, M., 1999. Severn-Trent sand: a kinematic-hardening constitutive model: the $\mathrm{q}-\mathrm{p}$ formulation. Géotechnique 49 (5), 595614. https://doi.org/10.1680/geot.1999.49.5.595.

Giretti, D., Fioravante, V., 2017. A correlation to evaluate cyclic resistance from CPT applied to a case history. Bull. Earthq. Eng. 15 (5), 1965-1989. https://doi.org/10.1007/s10518-016-0057-7.

Giretti, D., Fioravante, V., Been, K., Dickenson, S., 2018. Mechanical properties of a carbonate sand from a dredged hydraulic fill. Géotechnique 68 (5), 410-420. https://doi.org/10.1680/jgeot.16.P.304.

Ishihara, K., 1993. Liquefaction and flow failure during earthquakes. Géotechnique $43 \quad$ (3), 351-451. https://doi.org/ 10.1680/geot.1993.43.3.351.

Ishihara, K., Harada, K., Lee, W.F., Chan, C.C., Safiullah, A.M.M., 2016. Post-liquefaction settlement analyses based on the volume change characteristics of undisturbed and reconstituted samples. Soils Found. $56 \quad$ (3), 533-546. https://doi.org/10.1016/J. SANDF.2016.04.019.

ISO, 2004. ISO, TS 17892-9:2004, Geotechnical Investigation and Testing - Laboratory Testing of Soil - Part 9: Consolidated Triaxial Compression Tests on Water-Saturated Soils (2004). Switzerland, Geneva.

Japanese Geotechnical Society, 2009. JGS 0161 - Test methods for minimum and maximum densities of sands. Pub. L. No. JGS 01612009, 3 .

Jefferies, M., Been, K., 2000. Implications for critical state theory from isotropic compression of sand. Geotechnique 50 (4), 419-429. https:// doi.org/10.1680/geot.2000.50.4.419.

Jefferies, M., Been, K., 2015. Soil Liquefaction: A Critical State Approach, 2nd ed. CRC Press, Milton Park, Abingdon.

Jiang, M.D., Yang, Z.X., Barreto, D., Xie, Y.H., 2018. The influence of particle-size distribution on critical state behavior of spherical and non-spherical particle assemblies. Granular Matter 20 (4), 80. https:// doi.org/10.1007/s10035-018-0850-x.

Jorge, C., Vieira, A.M., 1997. Liquefaction potential assessment: Application to the Portuguese territory and to the town of Setubal. In Seco \& P. S. Pinto (Eds.), Earthquake geotechnical engineering: Seismic behaviour of ground and geotechnical structures (p. 401). Hamburg, Germany: A.A. Balkema.

Ladd, R.S., 1977. Specimen preparation and cyclic stability of sands. J. Geotech. Eng. Div. 103 (6), 535-547.

Lashkari, A., Falsafizadeh, S.R., Shourijeh, P.T., Alipour, M.J., 2020. Instability of loose sand in constant volume direct simple shear tests in 
relation to particle shape. Acta Geotech. 15 (9), 2507-2527. https://doi. org/10.1007/s11440-019-00909-4.

Lee, J.-S., Santamarina, J.C., 2005. Bender elements: performance and signal interpretation. J. Geotech. Geoenviron. Eng. 131 (9), 10631070. https://doi.org/10.1061/(ASCE)1090-0241(2005)131:9(1063).

Li, W., Coop, M.R., Senetakis, K., Schnaid, F., 2018. The mechanics of a silt-sized gold tailing. Eng. Geol. 241, 97-108. https://doi.org/10.1016/ j.enggeo.2018.05.014.

Liu, X., Yang, J., 2018. Shear wave velocity in sand: effect of grain shape. Géotechnique 68 (8), 742-748. https://doi.org/10.1680/jgeot.17.T.011.

Lunne, T., Knudsen, S., Blaker, Vestgården, T., Powell, J.J.M., Wallace, C.F., Ghanekar, R.K., 2019. Methods used to determine maximum and minimum dry unit weights of sand: Is there a need for a new standard? Can. Geotech. J. 56 (4), 536-553. https://doi.org/10.1139/ cgj-2017-0738.

Mesri, G., Vardhanabhuti, B., 2009. Compression of granular materials. Can. Geotech. J. 46 (4), 369-392. https://doi.org/10.1139/T08-123.

Miranda, L., Caldeira, L., Serra, J., Gomes, R.C., 2020. Dynamic behaviour of Tagus River sand including liquefaction. Bull. Earthq. Eng. 1-24. https://doi.org/10.1007/s10518-020-00881-5.

Molina-Gómez, F., Viana da Fonseca, A., Ferreira, C., Camacho-Tauta, J., 2020. Dynamic properties of two historically liquefiable sands in the Lisbon area. Soil Dyn. Earthquake Eng. 132. https://doi.org/10.1016/ j.soildyn.2020.106101 106101 .

Murthy, T.G., Loukidis, D., Carraro, J.A.H., Prezzi, M., Salgado, R., 2007. Undrained monotonic response of clean and silty sands. Géotechnique 57 (3), 273-288. https://doi.org/10.1680/geot.2007. 57.3.273.

Nguyen, H.B.K., Rahman, M.M., Fourie, A.B., 2020. How particle shape affects the critical state, triggering of instability and dilatancy of granular materials - results from a DEM study. Géotechnique 1-16. https://doi.org/10.1680/jgeot.18.p.211.

Nova, R., 1982. A constitutive model for soil under monotonic and cyclic loading. In: Pande, G., Zienkiewicz, O. (Eds.), Soil Mechanics Transient and Cyclic Loads. Wiley, Chichester, UK, pp. 343-373.

Papadimitriou, A.G., Dafalias, Y.F., Yoshimine, M., 2005. Plasticity modeling of the effect of sample preparation method on sand response. Soils Found. 45 (2), 109-123. https://doi.org/10.3208/sandf.45.2_109.

Pestana, J.M., Whittle, A.J., 1995. Compression model for cohesionless soils. Géotechnique 45 (4), 611-631. https://doi.org/ 10.1680/geot.1995.45.4.611.

Qadimi, A., Coop, M.R., 2007. The undrained cyclic behaviour of a carbonate sand. Géotechnique 57 (9), 739-750. https://doi.org/ 10.1680/geot.2007.57.9.739.

Ramos, C., Ferreira, C., Molina-Gómez, F., Viana da Fonseca, A., 2019. Critical state lines of Portuguese liquefiable sands. E3S Web of Conferences 92, 06003. https://doi.org/10.1051/e3sconf/20199206003.

Reid, D., Fourie, A., Ayala, J.L., Dickinson, S., Ochoa-Cornejo, F., Fanni, R., Suazo, G., 2020. Results of a critical state line testing round robin programme. Géotechnique 1-49. https://doi.org/10.1680/ jgeot.19.p.373.

Robertson, P.K., 2009. Interpretation of cone penetration tests - a unified approach. Can. Geotech. J. 46 (11), 1337-1355. https://doi.org/ 10.1139/T09-065.

Roscoe, K.H., Schofield, A.N., Wroth, C.P., 1958. On the yielding of soils. Géotechnique 8 (1), 22-53. https://doi.org/10.1680/geot.1958.8.1.22.

Salgado, F., 2009. Siting-Downtown Lisbon Metro blue line. In Lecture. MERCEA08, Seismic Engineering International Conference commemorating the 1908 Messina and Reggio Calabria Eartquake. Calabria, Italy.

Salgado, F., 2019. Liquefaction - Causes and effects. In: Silvestri, F., Moraci, N. (Eds.), Earthquake Geotechnical Engineering for Protec- tion and Development of Enviroment and Constructions. CRC Press/ Balkema, Rome, Italy, pp. 415-422.

Santamarina, J.C., Cho, G.C., 2004. Soil behaviour: The role of particle shape. In: Jardine, R.J., Potts, D.M., Higgins, K.G. (Eds.), . In: Advances in geotechnical engineering: The Skempton conference, Vol. 1. Thomas Telford, London, pp. 604-617. https://doi.org/10.1680/ AIGEV1.32644.0035.

Santamarina, J.C., Klein, K.A., Fam, M.A., 2001. Soils and waves. J. Wiley \& Sons.

Sarkar, D., Goudarzy, M., König, D., 2019. An interpretation of the influence of particle shape on the mechanical behavior of granular material. Granular Matter 21 (3), 53. https://doi.org/10.1007/s10035019-0909-3.

Sarkar, D., Goudarzy, M., König, D., Wichtmann, T., 2020. Influence of particle shape and size on the threshold fines content and the limit index void ratios of sands containing non-plastic fines. Soils Found. 60 (3), 621-633. https://doi.org/10.1016/j.sandf.2020.02.006.

Shipton, B., Coop, M.R., 2012. On the compression behaviour of reconstituted soils. Soils Found. 52 (4), 668-681. https://doi.org/ 10.1016/j.sandf.2012.07.008.

Soares, M., Viana da Fonseca, A., 2016. Factors affecting steady state locus in triaxial tests. Geotech. Test. J. 39 (6), 20150228. https://doi. org/10.1520/GTJ20150228.

Torres-Cruz, L.A., Santamarina, J.C., 2020. The critical state line of nonplastic tailings. Can. Geotech. J. 57, 1508-1517. https://doi.org/ 10.1139/cgj-2019-0019.

Verdugo, R., Ishihara, K., 1996. The steady state of sandy soils. Soils Found. 36 (2), 81-91. https://doi.org/10.3208/sandf.36.2_81.

Viana da Fonseca, A., Ferreira, C., Fahey, M., 2009. A framework interpreting bender element tests, combining time-domain and frequency-domain methods. Geotech. Test. J. 32 (2). https://doi.org/ 10.1520/GTJ100974 100974.

Wei, L.M., Yang, J., 2014. On the role of grain shape in static liquefaction of sand-fines mixtures. Géotechnique 64 (9), 740-745. https://doi.org/ 10.1680/geot.14.T.013.

Winter, M.J., Hyodo, M., Wu, Y., Yoshimoto, N., Hasan, M. Bin, Matsui, K., 2017. Influences of particle characteristic and compaction degree on the shear response of clinker ash. Eng. Geol. 230, 32-45. https://doi.org/10.1016/j.enggeo.2017.09.019.

Xiao, Y., Long, L., Matthew Evans, T., Zhou, H., Liu, H., Stuedlein, A. W., 2019. Effect of particle shape on stress-dilatancy responses of medium-dense sands. J. Geotech. Geoenviron. Eng. 145 (2), 04018105. https://doi.org/10.1061/(asce)gt.1943-5606.0001994.

Yamashita, S., Kawaguchi, T., Nakata, Y., Mikamt, T., Fujiwara, T., Shibuya, S., 2009. Interpretation of international parallel test on the measurement of G max using bender elements. Soils Found. 49 (4), 631-650. https://doi.org/10.3208/sandf.49.631.

Yang, J., Luo, X.D., 2015. Exploring the relationship between critical state and particle shape for granular materials. J. Mech. Phys. Solids 84, 196-213. https://doi.org/10.1016/j.jmps.2015.08.001.

Yang, J., Wei, L.M., 2012. Collapse of loose sand with the addition of fines: the role of particle shape. Géotechnique 62 (12), 1111-1125. https://doi.org/10.1680/geot.11.P.062.

Zheng, J., Hryciw, R.D., 2015. Traditional soil particle sphericity, roundness and surface roughness by computational geometry. Géotechnique 65 (6), 494-506. https://doi.org/10.1680/geot.14.P.192.

Zheng, J., Hryciw, R.D., 2016. Index void ratios of sands from their intrinsic properties. J. Geotech. Geoenviron. Eng. 142 (12), 06016019. https://doi.org/10.1061/(asce)gt.1943-5606.0001575.

Zheng, J., Hryciw, R.D., Ventola, A., 2017. Compressibility of sands of various geologic origins at pre-crushing stress levels. Geotech. Geol. Eng. 35 (5), 2037-2051. https://doi.org/10.1007/s10706-017-0225-9. 